\title{
The role of eye height in perceiving affordances and object dimensions
}

\author{
MARYJANE WRAGA \\ Emory University, Atlanta, Georgia
}

\begin{abstract}
In four experiments on perceived object height and width, the effects of shifting participants' effective eye height $(\mathrm{EEH})$ on affordance (intrinsic) and apparent size (extrinsic) judgments were contrasted. In Experiment 1, EEH shifts produced comparable overestimations of height in intrinsic and extrinsic tasks. A similar result was found with a more abstract extrinsic height task (Experiment 2). However, Experiment 3 revealed a dissociation between intrinsic and extrinsic tasks of perceived width. Affordance judgments were affected by EEH shifts, whereas apparent size judgments were not. Experiment 4 compared participants' performance on comparable extrinsic tasks of height and width. Height judgments were affected by EEH shifts, but width judgments were again unaffected. It is concluded that eye height may be a more natural metric for object height than for width. Moreover, this difference reflects a basic flexibility within the human visual system for selectively attuning to the most accessible sources of size information.
\end{abstract}

In recent years, researchers have demonstrated that eye height $(\mathrm{EH})$ plays a major role in the perception of affordances, such as the passability of apertures (Warren \& Whang, 1987) and the steponability of stair risers (Mark, 1987; Mark \& Vogele 1987; Warren, 1984). Its role in apparent-size perception has been less clear. Studies manipulating EH in pictures have produced both strong (Rogers, 1996) and weak (Bingham, 1993) effects for judgments of relative object size. Empirical manipulations of $\mathrm{EH}$ in real scenes have also produced ambiguous results for judgments of absolute size (Stoper, 1990; Stoper \& Bautista, 1992; Wraga \& Neisser, 1995). Despite the potential theoretical significance of EH scaling, few attempts have been made to clarify its role in size perception.

The notion of EH scaling was developed in the context of Gibson's (1979) ecological approach to perception. Gibson (1979) described the perceived environment in terms of affordances: what the environment offers an observer with reference to his or her action capabilities. For instance, an object of solid substance and sufficient breadth standing at knee height affords sitting-on. An object no wider than the digit span of the hand affords grasping. In specifying behavioral potential, affordances necessarily relate properties of the environment to the observer's

The research reported here was conducted as part of a doctoral dissertation at Emory University. I am indebted to Ulric Neisser for his guidance on this project. I thank, John Pani, Ronald Boothe, Scott Lilienfeld, and two anonymous reviewers for comments on earlier drafts of the manuscript. I also thank Viorica Marian, Andrew Shim, Dannon Baker, and Tamara Rothenberg for assistance in data collection. Correspondence concerning this article should be addressed to $\mathrm{M}$. Wraga, Department of Psychology, Harvard University, William James Hall 840, 33 Kirkland Street, Cambridge, MA 02138 (e-mail: mjwraga@ wjh.harvard.edu). relevant body dimensions. Information such as eye height is thus potentially available as an intrinsic metric, referring to the body and relating to action. This is in contrast to extrinsic metrics, such as inches or meters, which are defined less obviously with respect to the observer (Mark, 1987; Warren, 1984; Warren \& Whang, 1987).

Sedgwick (1973) was the first to formalize a theory of EH scaling, in connection with the horizon-ratio relation. In an open, level environment, the visible horizon is always redundant with an observer's horizontal line of gaze. Therefore, if the observer stands on flat ground, his or her eye level intersects a distant object at the horizon line. Sedgwick's original formulation of the horizonratio relation was that perceived object height is specified relative to the horizon. However, the horizon is often not explicitly defined - in a crowded city, for example, or indoors. In such instances, the horizon is specified implicitly via several sources, including the point of expansion of optic flow fields and the convergence and increasing density of texture on both the floor and walls.

Throughout this paper, the concept of EH will be used in two ways. EH refers to the actual height of an observer's line of gaze off the level floor. Effective eye height (EEH) refers to the projection of the observer's EH into the environment, which can be used to scale the sizes of objects. Because EEH is redundant with the implicit horizon, it can be specified by the same visual information mentioned above. However, it is also available through a combination of three vestibular/ocular-motor cues: the vertical orientation of the head with respect to gravity, the position of the eye relative to the head, and the location of a point of fixation on the retina (Matin \& $\mathrm{Li}$, 1992).

Figure 1 shows how the height of an object can be scaled to EEH. The actual ratio of total object height $(Y)$ to the portion of the object below $\mathrm{EEH}(E)$ is equal to the corre- 
sponding ratio in the projection at the eye. Expressed in terms of visual angle,

$$
Y / E=1+\tan (y-e) / \tan e,
$$

where $y-e$ is the visual angle subtended by the portion of the object above the point of EEH intersection and $e$ is the visual angle of the object from EEH intersection to the object's base. Thus, a retinally available ratio specifies the relationship between the height of the object and the EEH of the observer. This relationship remains constant, regardless of the distance between object and observer. It provides the observer with ratio information about the size of the object, relative to EEH. However, if $\mathrm{EH}$ is a known value, the absolute height of the object can be determined.

Another implication of the horizon-ratio relation is that $\mathrm{EH}$ information can be used to determine the dimensions of objects perpendicular to the line of sight, such as width (see Figure 2). In both cases, environmental sizes are scaled to a known dimension of the perceiving individual.

The horizon-ratio relation is conceptually similar to another invariant source of information proposed by Gibson (1950). Gradients of texture can be used to scale the relative size or distance of an object; if the absolute size of one element is known (through either body scaling or familiar size), it can be used to scale the absolute size of the object. The important similarity between EH information and texture gradients is that neither requires perceived distance for size scaling. This is in sharp contrast with the classical account of size perception, which holds that the perceived size of an object is dependent on both its visual angle size and its perceived distance from the viewer (Helmholtz, 1867/1962). Accordingly, early size experiments concentrated on systematically manipulating these variables, while ignoring other relevant information and the potential significance of the tasks viewers were asked to perform. These experiments relied on response measures unrelated to the viewer, such as adjusting one object to match the size of an arbitrary test object (Holway \& Boring, 1941) or choosing a size match from an array of objects (Leibowitz, Pollard, \& Dickerson, 1966). Proponents of the ecological view have asserted that these types of extrinsic size measures hold little or no significance for perceivers (Fitch \& Turvey, 1978; Warren, 1984; Warren \&
Whang, 1987) and should be replaced by action-related intrinsic measures. Citing differences in meaningfulness between the two measures, Gibson $(1977,1979)$ hypothesized that extrinsic tasks should be more difficult to perform than comparable intrinsic ones.

Researchers have subsequently demonstrated that intrinsic tasks, such as perceiving affordances, could be tested empirically and that they involve EH scaling. Warren (1984) found that participants' judgments of critical riser height - the highest step onto which they could climb without reverting to a hands-and-knees posture-were a constant proportion (.88) of leg length, regardless of the height of the participant. Further studies by Mark (1987; Mark \& Vogele, 1987) suggested that participants were scaling the riser heights to standing EH. The critical boundary for steponability was found to be $.45 \mathrm{EH}$. Warren and Whang (1987) provided the strongest evidence for EH scaling by testing the passability of apertures under conditions in which EEH was directly manipulated. With EEH reduced via introduction of a false floor into the field of view, participants systematically overestimated aperture widths. To demonstrate that such judgments were made irrespective of distance calculations, a separate condition tested participants' judgments of distance with and without the false floor. No differences were found. This provided clear evidence that the shift in the perceived width of the aperture was not attributable to a shift in its perceived absolute distance.

The effect of EEH manipulations on apparent size has also been tested, albeit with inconsistent results. Using a pitch box apparatus to manipulate EEH, Stoper (1990; Stoper \& Bautista, 1992) examined its effect on perceived object height. In accordance with the horizon-ratio relation, participants systematically underestimated targets when the pitch box was shifted up and overestimated targets when the box was shifted down. Wraga and Neisser (1995) attempted to extend Stoper's findings by examining the effects of EH manipulations on both perceived height and perceived width. Participants looked through a "periscope,"which shifted EEH up or down via mirrors. Under- and overestimations of perceived size were found in both conditions, but the magnitude of the biases was smaller than that found by Stoper. Wraga and Neisser concluded that other factors, such as depth cues, might have diminished the utility of $\mathrm{EH}$ information in their display.

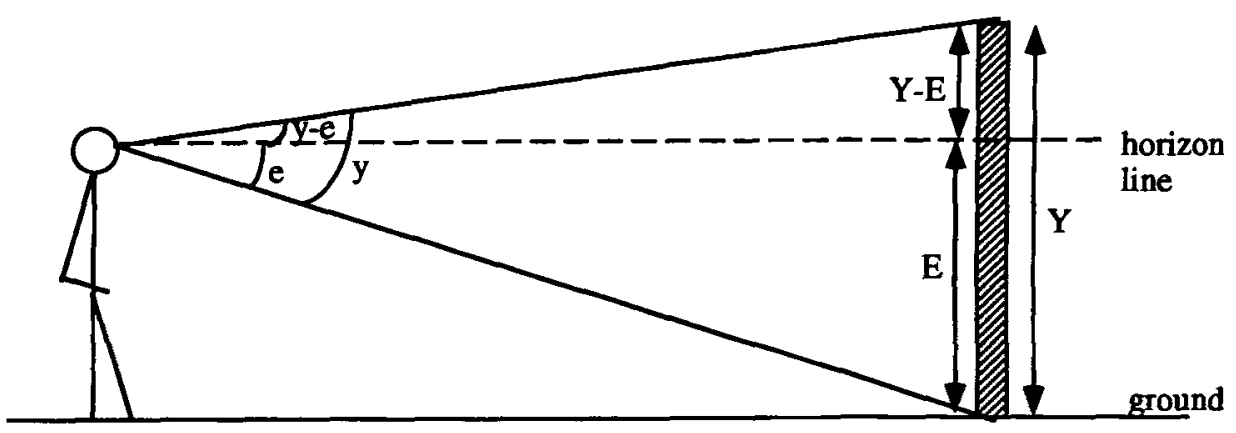

Figure 1. The geometry of the horizon ratio for height. 


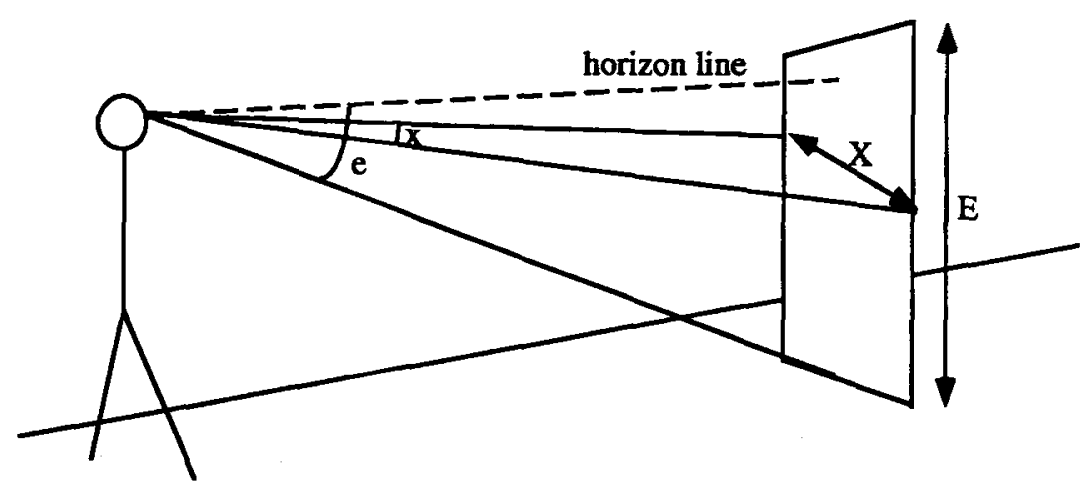

Figure 2. The geometry of the horizon ratio for width.

The goal of the present research was to provide a more comprehensive analysis of the role of eye height in size perception by comparing its effect on two size-related judgments of object height and width. The perception of affordances has been shown to involve EH scaling; therefore, a direct comparison between affordance (intrinsic) and standard-comparison (extrinsic) size tasks seemed an efficient strategy. Affordance tasks require judgments of absolute size: The observer must compare an object's dimensions with the known value of his or her EEH. In contrast, size matches or comparisons with a standard are made by comparing the retinal sizes of two objects, without necessarily knowing the physical size of either. Thus, they could be made independently of EH information. In cases in which the standard is out of sight of the observer, absolute judgments are required. However, they could still be referred to the external standard and not to the observer's EH. The apparent sizes of the objects would derive from retinal size and perceived absolute distance, as in the classical account of size perception (Helmholtz, 1867/1962).

The main hypothesis of the present study was as follows. If such intrinsic tasks as judging the climbability of a step or the passability of a doorway are made by scaling the objects to a viewer's own EH, surreptitiously shifting EEH should affect critical affordance boundaries. On the other hand, if such extrinsic tasks as comparing an object with a standard do not require EH information, EEH shifts should not affect them. Perceived size in the latter case could be derived from distance information given by motion parallax. Extrinsic judgments might also be based on ratios of floor texture units, which do not change with EH manipulations. Either way, reliance on a standard unrelated to EH would result in immunity to shifts of EEH.

Four experiments were conducted to test this hypothesis. In all, EEH was manipulated by using Warren and Whang's (1987) false floor technique. In Experiment 1, the effects of shifting EEH on perceived object height were examined. For the affordance (intrinsic) task, participants judged the steponability of steps; for the apparent size (extrinsic) task, they compared the height of each step riser to a standard rod. It was predicted that the false floor would produce a systematic lowering of critical bound- aries in the intrinsic task but that this effect would be diminished or absent in the extrinsic task. Experiment 2 was a replication of Experiment 1 with more abstract size judgments. In the extrinsic task, participants compared the step heights with a remembered standard. Experiment 3 tested the effects of manipulating EEH on perceived object width. For the intrinsic task, participants judged the passability of doorways; for the extrinsic task, they compared the width of each doorway with a remembered standard. It was again predicted that the false floor would have a greater effect on the EH-scaled affordance judgments than on comparisons with a remembered standard. Finally, in Experiment 4, judgments of object height and width were directly compared, within the extrinsic task only.

\section{EXPERIMENT 1}

In the first experiment, judgments of object height were examined. As in Warren and Whang's (1987) experiment, EEH was manipulated by surreptitiously introducing a false floor into the participants' field of view (see Figure 3 ). In the present setup, the false floor was raised $17 \mathrm{~cm}$ off the ground, which served to reduce EEH by the same amount. If participants use EH-scaled information, objects should appear larger in the raised (false floor) condition, than in the flat (continuous floor) condition, resulting in a corresponding downward shift in the perceived critical boundary for stepping. If perceived steponability in the intrinsic (affordance) task depends entirely on such information, critical boundaries should be reduced by exactly $7.6 \mathrm{~cm}$ (i.e., $.45 \times 17$ ), according to the EH ratio for critical riser height reported by Mark (1987). Because the standard used in the extrinsic task also corresponded to $.45 \mathrm{EH}$ (see below), total reliance on $\mathrm{EH}$ would also produce a $7.6-\mathrm{cm}$ reduction in that condition. However, it was predicted that the participants would make more use of EH in the affordance task and, hence, that the shift induced by the false floor would be larger for intrinsic than for extrinsic judgments. In accord with the ecological viewpoint, it was also predicted that the more meaningful intrinsic judgments would reflect greater accuracy (in terms of both variable and constant error) than would the extrinsic ones. 


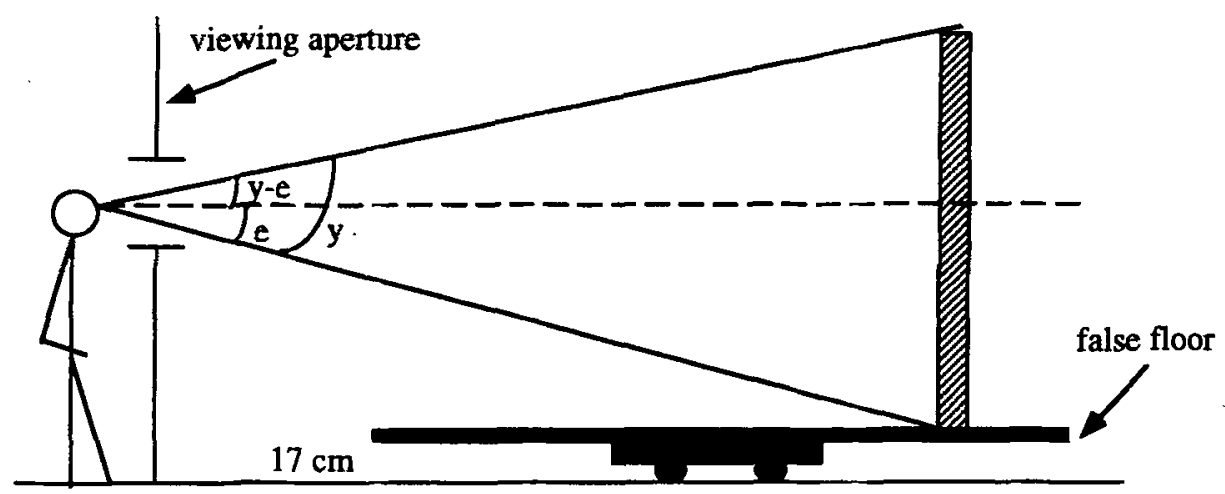

Figure 3. Schematic drawing of the false floor. The object subtends a smaller visual angle (e) from eye level to its base (cf. Figure 1), which results in an overestimation of height.

\begin{abstract}
Method

\section{Participants}

Twenty-four Emory University undergraduates (16 female, 8 male) participated in the experiment as part of a class research credit requirement. All the participants were tested individually; none was aware of the hypothesis being tested.
\end{abstract}

\section{Equipment}

Chamber. A $4.9 \times 1.8 \times 2.4 \mathrm{~m}(1 \times \mathrm{w} \times \mathrm{h})$ chamber was built in the Emory Perception Laboratory for the experiment (see Figure 4). Access to the back of the experimental room was closed off by a full-length white curtain, which ran from the right side of the chamber to the wall. Thus, the participants had no information regarding the length of the chamber or the length of the Perception Laboratory itself. The chamber was lighted with fluorescent lights, mounted on the ceiling out of the participant's view. The lights were bright enough to provide normal room illumination without casting shadows. The inside of the chamber walls were seamless and were painted a light tan color. The carpet was dark gray, with a visible but not striking texture. A large, seamless black cloth was fitted over the far end of the chamber, and a 2-cm black floor moulding running the entire width of the chamber was attached where the cloth met the floor. A small doorway was cut out of the right-hand wall near the far end, for access to the stimuli. The viewing (opposite to far) end contained a $103 \times 15.5 \mathrm{~cm}$ vertical viewing aperture. A small black curtain hung over the outside of the aperture. On the inside of the aperture, a $20 \times 20 \mathrm{~cm}$ shelf was attached by two metal poles so that its height was adjustable by $103 \mathrm{~cm}$.

A $17.5 \times 9 \times 16 \mathrm{~cm}$ rectangular reduction tube was positioned on the shelf so that its $2.5-\mathrm{cm}$-diameter peephole rested against the outside of the chamber wall. The peephole could be adjusted to the participant's EH by raising or lowering the shelf. The far end of the reduction tube contained an $11 \times 3.5 \mathrm{~cm}$ oval opening, which created an aperture of similar shape and size. The field of view of the tube subtended $34^{\circ} \times 11^{\circ}$ of visual angle. The participants could see the step, approximately $0.5 \mathrm{~m}$ of the black wall behind and above it, and about $10 \mathrm{~cm}$ of the floor in front of the step. The walls and ceiling of the chamber were not visible.

False floor. The false floor in the chamber consisted of a $213 \times$ $122 \times 1.5 \mathrm{~cm}$ piece of plywood mounted on a $94 \times 64 \times 16.5 \mathrm{~cm}$ dolly (see Figure 3). When assembled, the total height of the false floor was $17 \mathrm{~cm}$ off the chamber floor, which effectively reduced field-of-view visual angle (from visible floor to observer's line of gaze) by $2^{\circ}$. In order to create the appearance of a continuous surface, the false floor was covered with carpet identical to that of the Perception Laboratory (and, hence, the experimental chamber). A $2-\mathrm{cm}$ black moulding identical to that of the chamber floor was fixed to the far end of the false floor. In the raised condition, the false

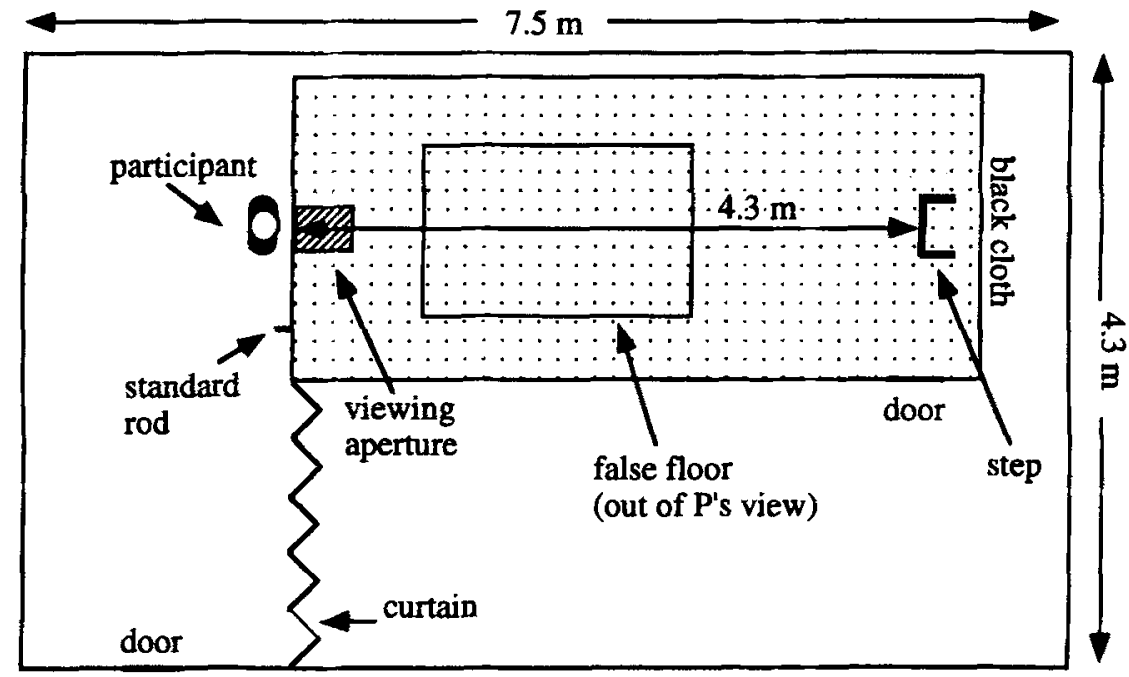

Figure 4. Overhead view of the experimental setup. The false floor is in position for the flat condition. 
floor was rolled to the far end of the chamber so that its moulding end abutted the cloth-covered wall. In the flat condition, it was rolled back to the near end of the chamber, out of the participant's view.

\section{Stimulus Materials}

Fourteen white, rectangular foam-core "steps" were used, each of which was created by affixing a $50 \times 25 \mathrm{~cm}$ "tread" perpendicular to a 50-cm wide "riser" of varying height. The heights ranged from 38.5 to $90.5 \mathrm{~cm}\left(5^{\circ}-12^{\circ}\right.$ of visual angle $)$ in $4-\mathrm{cm}$ increments. The steps were presented $0.61 \mathrm{~m}$ in front of the back wall of the chamber, $4.3 \mathrm{~m}$ from the participant.

For the extrinsic task, fourteen 2-cm-diameter red dowels, whose lengths exactly matched the range of the riser heights, were available. One rod was used as the standard for each participant-namely, the one closest to $.45 \mathrm{EH}$ (the critical ratio for steponability). This permitted comparison of judgments across tasks. The standard rod was suspended vertically on the outside of the chamber wall, $63 \mathrm{~cm}$ to the right of the peephole, at a height above the tallest participant's EH $(1.9 \mathrm{~m})$.

\section{Size Judgments}

Intrinsic. The participants made a "yes" or a "no" judgment as to whether they could step onto the presented step in a normal way (i.e., without reverting to a hands-and-knees action). The experimenter demonstrated actions illustrating both "yes" and "no" judgments. The participants were also shown the endpoints of the range of steps.

Extrinsic. The participants compared the height of each step with the length of the standard rod. They responded "yes" if they thought the step height was equal to or shorter than the rod; a "no" meant that the step height was greater than the rod. Before commencing judgments, the participants were shown the endpoints of the step range.

\section{Eye Height Judgments}

At the end of each block of size trials, two perceived eye height (PEH) judgments were made (one ascending and one descending). The participants were first asked to visualize the intersection of their horizontal line of gaze with the wall against which the blocks were presented. The experimenter then moved a laser-produced spot of light up and down on the wall, and the participants indicated where it met their horizontal line of gaze. The mean of these judgments was used for analysis.

\section{Procedure}

Each participant performed in two sessions, usually 2 days apart. In one session, all the judgments were intrinsic; in the other, judgments were extrinsic. Each session involved judgments in both raised and flat floor conditions.

The participants' actual standing EHs were first measured. They were then sent out of the room while the experimenter and an assistant adjusted the viewing tube to the correct peephole height. When they returned, the size trials began. The participants closed the small, black curtain between trials so that they could not see the stimuli being changed. After the first block of size trials, $\mathrm{PEH}$ judgments were made. The participant was then instructed to leave the room briefly; during this "break," the false floor was moved into (or out of) position. Upon return, the participant completed another block of size judgments, followed by another set of PEH judgments.

In debriefing, all the participants were asked whether they had noticed the false floor in the raised condition.

\section{Design}

The orders of the two size tasks (intrinsic and extrinsic) and two floor conditions (flat and raised) were counterbalanced across participants. Each block of size trials contained three sets of judgments. Each set consisted of one ascending and one descending presentation of stimuli; the participants were always informed of which one was occurring. Critical riser height was determined by using the method of limits. For each trial, the blocks were presented until a change in response (i.e., from "no" to "yes" in descending, from "yes" to "no" in ascending) occurred twice consecutively. In the descending presentation, the interval between the last "no" and the first "yes" constituted the critical climbability boundary; for the ascending presentation, it was the interval between the last "yes" and the first "no." Both judgments of a given set were then averaged, for a total of three scores in each floor condition. The sequence of ascending/ descending orders was counterbalanced across participants.

\section{Results}

\section{Size Judgments}

No participants reported noticing the false floor. Mean perceived size judgments and critical boundaries, as a function of task and floor condition, are shown in Figure 5. As was expected, for the intrinsic task, perceived critical boundaries were lower in raised $(M=62.64 \mathrm{~cm})$ than in flat $(M=66.14 \mathrm{~cm})$ conditions. That is, the step chosen as the critical boundary in the raised condition was lower than that in the flat condition. However, contrary to the hypothesis, a similar effect appeared for extrinsic judgments: Perceived sizes were lower in raised $(M=60.67 \mathrm{~cm})$ than in flat $(M=63.86 \mathrm{~cm})$ conditions. A 2 (floor order) $\times 2$ (task order) $\times 2$ (task) $\times 2$ (floor) mixed design analysis of variance (ANOVA) revealed a main effect of floor $[F(1,20)=52.81, p<.0001]$ but no effects of floor order, task order, or task. The predicted interaction of task $\times$ floor did not appear $[F(1,20)=0.09$, $p=.764]$. However, an unpredicted floor order $\times$ task $\times$ floor interaction was significant $[F(1,20)=5.28, p<$ $.033]$ : In the intrinsic task, the participants who made

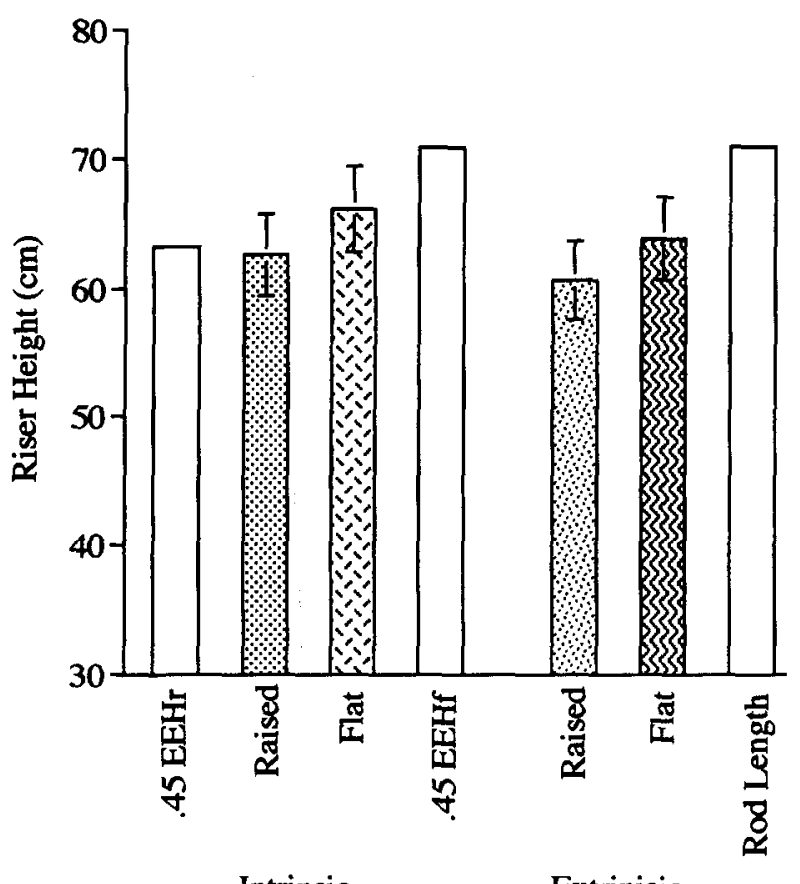

Intrinsic

Extrinisic

Figure 5. Critical boundaries, judged sizes, and standard errors in Experiment 1. The white bars correspond to predicted values. 
judgments in the flat condition after the raised condition tended to make especially high critical-boundary settings $(M=70.6 \mathrm{~cm})$. In other words, the appearance of the false floor first in the intrinsic task tended to create more of a contrast between respective critical size boundaries.

To assess the magnitude of the false floor effect, flat judgments were subtracted from raised ones. The means of these difference scores (right-hand column, Table 1) were virtually the same in both tasks (intrinsic, $M=$ $3.50 \mathrm{~cm}$; extrinsic, $M=3.19 \mathrm{~cm}$ ). These values were slightly less than half $(44 \%)$ of what was predicted by the EH model. There were no significant correlations between shifts in PEH induced by the false floor and analogous shifts in critical boundaries or judged sizes [intrinsic, $r(24)=.034, p>.05$; extrinsic, $r(24)=.029, p>.05]$.

\section{Accuracy}

Judgment accuracy was analyzed in two ways. Constant error was assessed by comparing the participants' judgments in both tasks with actual (extrinsic) or estimated (intrinsic) values. Variable error was assessed by examining the spread of the participants' judgments around their means.

Constant error. In general, the participants tended to slightly overestimate the step risers in both tasks. In the extrinsic task, a comparison of size judgments with the actual size of the standard yielded an $11 \%$ overestimation in the flat condition and a $17 \%$ overestimation in the raised condition (Table 1). Judged critical boundaries in the intrinsic task were compared, not with actual critical boundaries (which were not measured), but with estimates based on Mark (1987). He found that participants' actual critical boundaries averaged $.45 \mathrm{EH}$. Judged critical boundaries in the present study were compared with estimates based on the same proportion of participants' EEH in each respective floor condition (Table 1) to create the closest approximation to accuracy. These ratios revealed slight overestimations in the flat (7\%; compared with $.45 \mathrm{EEH}_{\mathrm{f}}$ ) and raised (1\%; compared with .45 $\mathrm{EEF}_{\mathrm{r}}$ ) conditions.

Because accuracy for intrinsic and extrinsic flat judgments was based on the same baseline value, a direct comparison between both conditions was possible. No sig- nificant difference in constant error was found $[t(23)=$ $-1.30, p=.208]$.

Variable error. In every condition, three overall size judgments were recorded for each participant. The first panel of Table 2 shows mean standard deviations of these judgments by task and floor conditions. Contrary to the hypothesis, judgments were generally consistent, regardless of task. A 2 (task) $\times 2$ (floor) ANOVA performed on the standard deviations revealed no effects of task $[F(1,23)=0.10, p=.757]$ or floor $[F(1,23)=2.11, p=$ $.160]$ and no significant interactions.

\section{Eye Height Judgments}

Differences in PEH across floor conditions were found. Table 3 shows the means in all four conditions, together with their predicted values (the predicted value for the flat condition- $\mathrm{EEH}_{\mathrm{f}}$ - was the mean of the 24 participants' measured eye heights; for the raised condition, the predicted value $-\mathrm{EEH}_{\mathrm{r}}-$ was $17 \mathrm{~cm}$ less). Averaged across size tasks, mean $\mathrm{PEH}$ in the raised condition $(M=123 \mathrm{~cm})$ was $8.78 \mathrm{~cm}$ less than that in the flat condition $(M=131.78 \mathrm{~cm})$. This difference was significant $[t(23)=-6.28, p<.0001]$. Judgments in both conditions were also highly variable (raised, $S D=16.19 \mathrm{~cm}$; flat, $S D=17.67 \mathrm{~cm}$ ). The mean PEH difference between floor conditions of $8.78 \mathrm{~cm}$ was only about half $(52 \%)$ of what would be predicted on the basis of the actual height of the false floor $(17 \mathrm{~cm})$.

Judged EHs were appreciably below actual EHs. Averaged across size tasks, PEH in the flat condition was $25.76 \mathrm{~cm}$ below $\mathrm{EEH}_{\mathrm{f}}$; in the raised condition, mean PEH was $17.54 \mathrm{~cm}$ below $E H_{\mathrm{r}}$. A 2 (task) $\times 2$ (floor) ANOVA performed on these difference scores (predicted values $\mathrm{PEH})$ yielded a main effect of floor $[F(1,23)=34.54$, $p<.0001$ ], indicating that the participants tended to underestimate PEH less when the false floor was present. This tendency could account for the unexpectedly small effect of the false floor on PEH judgments. There was no effect of task and no significant interactions.

\section{Discussion}

The results of Experiment 1 were somewhat unexpected. The presence of the false floor did significantly reduce

Table 1

Size Judgments, Critical Boundaries, and Difference Scores (Flat - Raised) in Experiment 1

\begin{tabular}{|c|c|c|c|c|c|c|c|}
\hline \multirow[b]{3}{*}{ Task } & \multirow[b]{3}{*}{ Measure } & \multicolumn{4}{|c|}{ Condition } & & \\
\hline & & \multicolumn{2}{|c|}{ Flat } & \multicolumn{2}{|c|}{ Raised } & \multicolumn{2}{|c|}{ Difference } \\
\hline & & $M$ & $S D$ & $M$ & $S D$ & $M$ & $S D$ \\
\hline \multirow[t]{3}{*}{ Intrinsic } & Judged critical boundary & 66.14 & 9.23 & 62.64 & 7.57 & 3.50 & 3.49 \\
\hline & Estimated critical boundary & 70.89 & 4.18 & 63.24 & 4.18 & & \\
\hline & Constant error ratio & \multicolumn{2}{|c|}{1.07} & \multicolumn{2}{|c|}{1.01} & & \\
\hline \multirow[t]{3}{*}{ Extrinsic } & Judged equivalent size & 63.86 & 6.67 & 60.67 & 6.53 & 3.19 & 1.77 \\
\hline & Actual size of standard & 70.89 & 4.18 & 70.89 & 4.18 & & \\
\hline & Constant error ratio & \multicolumn{2}{|c|}{1.11} & \multicolumn{2}{|c|}{1.17} & & \\
\hline
\end{tabular}

Note-Numbers are group means $( \pm S D)$ in centimeters. Judged critical boundaries in the intrinsic task were compared with estimates based on Mark (1987), who found that actual critical boundaries averaged .45 EH; they have been estimated at $.45 \mathrm{EEH}_{\mathrm{f}}$ and $.45 \mathrm{EEH}_{\mathrm{r}}$ for the flat and raised conditions, respectively. In the extrinsic task, the length of the standard rod varied from participant to participant, being set at $.45 \mathrm{EEH}_{\mathrm{f}}$. 
Table 2

Variable Error in Experiments 1-4

\begin{tabular}{|c|c|c|c|c|c|c|c|c|c|c|c|c|c|c|c|c|}
\hline \multirow[b]{3}{*}{ Condition } & \multicolumn{4}{|c|}{ Experiment 1} & \multicolumn{4}{|c|}{ Experiment 2} & \multicolumn{4}{|c|}{ Experiment 3} & \multicolumn{4}{|c|}{ Experiment 4} \\
\hline & \multicolumn{2}{|c|}{ Intrinsic } & \multicolumn{2}{|c|}{ Extrinsic } & \multicolumn{2}{|c|}{ Intrinsic } & \multicolumn{2}{|c|}{ Extrinsic } & \multicolumn{2}{|c|}{ Intrinsic } & \multicolumn{2}{|c|}{ Extrinsic } & \multicolumn{2}{|c|}{ Height } & \multicolumn{2}{|c|}{ Width } \\
\hline & $M$ & $S D$ & $M$ & $S D$ & $M$ & $S D$ & $M$ & $S D$ & $M$ & $S D$ & $M$ & $S D$ & $M$ & $S \bar{D}$ & $M$ & $S D$ \\
\hline Flat & 1.87 & 0.95 & 1.91 & 1.23 & 2.06 & 1.56 & 2.00 & 1.86 & 1.01 & 1.26 & 1.66 & 1.70 & 1.35 & 1.21 & 2.00 & 2.19 \\
\hline Raised & 1.69 & 1.08 & 1.50 & 0.98 & 1.82 & $\cdot 1.64$ & 2.12 & .1 .72 & 1.41 & 1.32 & 1.36 & 1.13 & 1.06 & 0.96 & 1.83 & 1.47 \\
\hline
\end{tabular}

Note-Mean within-subjects variability and SDs are in centimeters. In Experiment 1, variable error was calculated from the variance of three scores. In Experiments 2, 3, and 4, variable error was calculated from the variance of two scores.

the participants' judgments of the critical boundary of steponability. However, the participants showed approximately the same shift, induced by the raised floor, in the extrinsic condition, which was designed to be in line with more traditional size tasks. Furthermore, both tasks were performed with equal accuracy, in terms of both constant error and within-subjects variability. It appears that EH information is used not only in body-scaled affordance judgments, but also in simple judgments of vertical object size.

An alternative explanation is that the extrinsic task was not "abstract" enough: With the standard rod always present in the field of view, the participants might have first gauged it to some bodily dimension, such as leg length, and then scaled the steps accordingly, using EEH, as in the intrinsic condition. In fact, upon debriefing, one sixth of the participants reported using such a strategy. Given the fact that the standard was always in view, it is quite possible that other participants may have used an EH-scaling strategy without being aware of it.

The shift in critical size boundaries and size judgments was appreciably less $(44 \%)$ than would have been predicted from the geometry of the raised floor. It also fell short of the shift Warren and Whang (1987) obtained (65\% of the predicted value) in their experiment of perceived passability. It is possible that one or more distance cues in the scene conflicted with EH information, thereby diminishing its effect. One such candidate is elements of ground texture, whose number remained invariant across floor conditions and could have been used to scale riser height. However, such an explanation does not account for the participants' PEH judgments, which were underestimated substantially more than those reported elsewhere for similar distances (Mark, 1987; Warren \& Whang, 1987). Perhaps a more viable interpretation is that the reduction tube produced a frame effect (Koffka, 1935). Frame effects occur when the perception of a given stim- ulus is affected by the structure of its surrounding field of view. In order to accommodate a normal range of participant heights while keeping the false floor in view but unrecognizable as such, the viewing peephole in the current setup was not centered vertically, relative to the oval opening at the far end of the reduction tube. It was positioned $4 \mathrm{~cm}$ higher than the tube's vertical center. Thus, the participants' line of gaze may have unintentionally been "pulled" down relative to the center of the opening, which would result in general underestimations of PEH. This would also explain why underestimations of PEH were greater in the flat condition than in the raised condition: The addition of the false floor in the raised condition shifted the visual field up, relative to the frame of the reduction tube; as a result, the center of the visual field was higher, and underestimations were reduced (see Figure 6).

This interpretation suggests, at first glance, that the participants based their critical-boundary and size judgments on misperceived EH. However, the absence of a correlation between size shifts and PEH shifts implies that this is still an open question. Experiment 2 was designed to explore this issue further.

\section{EXPERIMENT 2}

Experiment 2 was a replication of Experiment 1, but implemented a more abstract extrinsic task. The participants compared the step risers to a remembered standard (24 in.). ${ }^{1}$ This method was intended to discourage the participants from utilizing overt EH-scaling strategies that may have been accessible in Experiment 1's extrinsic task. The length of the 24-in. standard was, on average, $39 \%$ of the participants' $\mathrm{EH}$; therefore, the predicted reduction of perceived height because of the false floor was $6.6 \mathrm{~cm}(.39 \times 17)$ in the extrinsic task. As in Experiment 1, the intrinsic task was a test of judged step-

Table 3

Perceived Eye Height (PEH) in Experiment 1

\begin{tabular}{|c|c|c|c|c|c|c|c|c|c|}
\hline \multirow[b]{2}{*}{ Condition } & \multicolumn{2}{|c|}{ Extrinsic } & \multicolumn{2}{|c|}{ Intrinsic } & \multicolumn{2}{|c|}{ Mean } & \multicolumn{2}{|c|}{ Predicted Value } & \multirow{2}{*}{$\begin{array}{c}\text { Difference } \\
(\mathrm{PEH}-\mathrm{EEH})\end{array}$} \\
\hline & $M$ & $S D$ & $M$ & $S D$ & $M$ & $S D$ & $M$ & $S D$ & \\
\hline Flat & 132.72 & 19.26 & 130.84 & 18.06 & 131.78 & 17.67 & 157.54 & 9.28 & -25.76 \\
\hline Raised & 123.82 & 16.84 & 122.18 & 16.62 & 123.00 & 16.19 & 140.54 & 9.28 & -17.54 \\
\hline Difference & & & & & 8.78 & & 17.00 & & -8.22 \\
\hline
\end{tabular}

Note-Means and $S D$ s are in centimeters. In the flat condition, the predicted value $\left(\mathrm{EEH}_{\mathrm{f}}\right)$ is the actual mean $\mathrm{EH}$ of the 24 participants. In the raised condition $\left(\mathrm{EEH}_{\mathrm{r}}\right)$, it is $17 \mathrm{~cm} \mathrm{less.}$ 

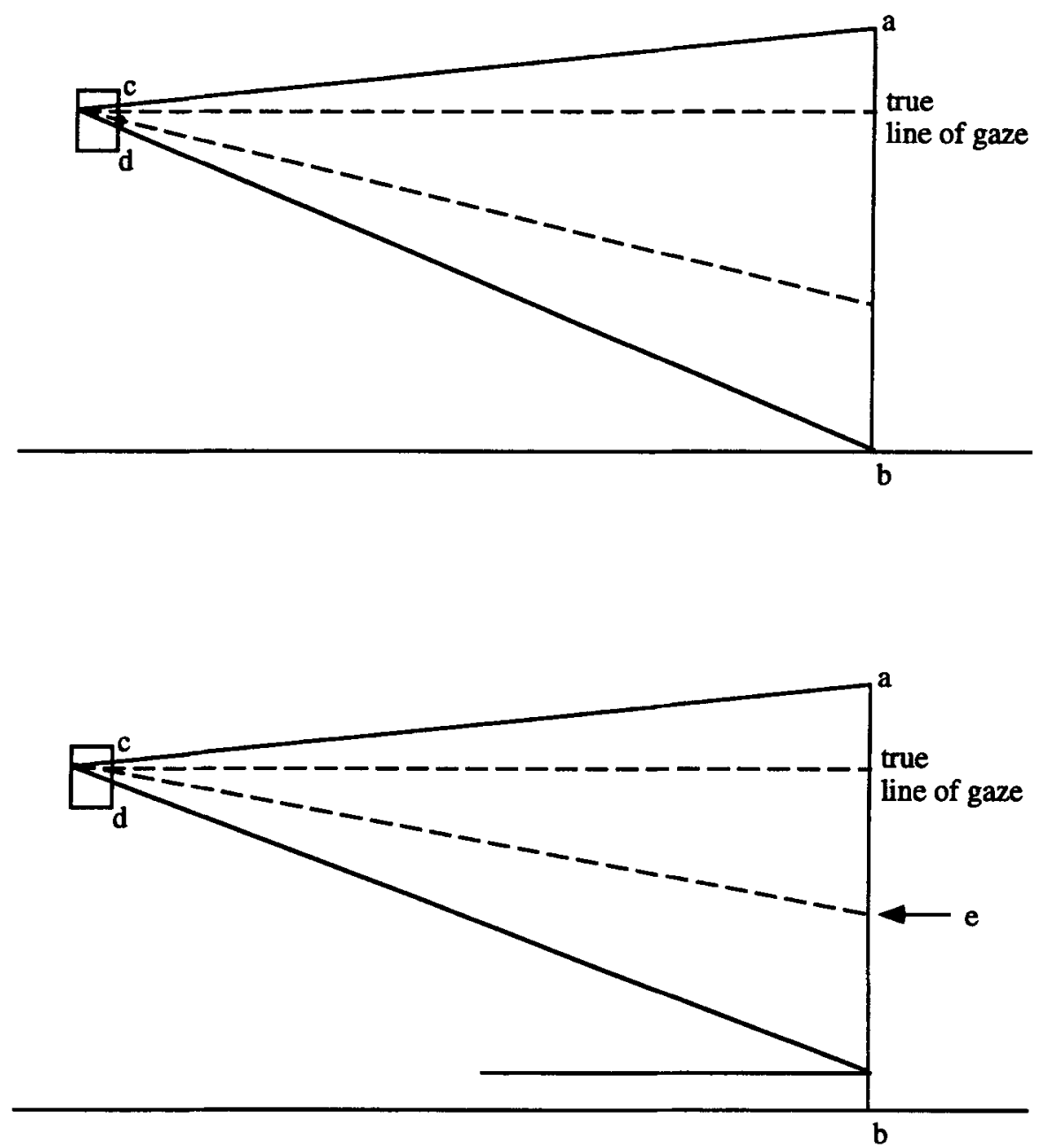

Figure 6. Frame effects of the viewing aperture. a-b refers to the distance between the top and the bottom of the visual field; $c-d$ refers to the distance between the top and the bottom of the reduction tube. Reliance on the vertical center of the reduction tube (indicated by a dot) results in underestimation of line of gaze (top). Addition of the false floor (bottom) shifts up the vertical center of the visual field (e), relative to the reduction tube, and underestimation is reduced.

onability; the predicted shift of critical boundaries thus remained $7.6 \mathrm{~cm}(.45 \times 17)$. Relative to these shifts, the main prediction again was that the false floor would have a greater effect on intrinsic judgments than on extrinsic ones. It was also expected that judgments in the intrinsic condition would be more accurate (in terms of constant and variable error) than those in the extrinsic condition.

The other major alteration involved changing the dimensions of the reduction tube, in order to see whether the gross underestimations of PEH found in Experiment 1 were due to an unintentional aperture framing effect. We centered the vertical dimension of the reduction tube aperture on the peephole as much as possible, while adhering to the constraint of keeping the false floor out of view for a normal range of participant heights. It was predicted that this manipulation would improve the accuracy of PEH estimates and would also increase the effect of the false floor on both PEH and size judgments.

\section{Method}

\section{Participants}

Twenty-four Emory summer students (19 female, 5 male) received $\$ 10$ each to participate in the experiment. All the participants were tested individually; none was aware of the hypothesis being tested.

\section{Equipment}

The equipment was essentially the same as that in Experiment 1, except that the far end of the reduction tube was changed. Its vertical extent was enlarged to $13.5 \mathrm{~cm}$, and it was repositioned so that the peephole was only $2.5 \mathrm{~cm}$ above the vertical center. This was the most vertical leeway that could be given without exposing the false floor through the viewing aperture. The field of view of the reduction tube subtended $40^{\circ} \times 11^{\circ}$ of visual angle.

\section{Stimulus Materials}

The foam-core steps from Experiment 1 were used for the intrinsic task. For the extrinsic task, the participants were shown a standard wooden yardstick that had been cut to $24 \mathrm{in}$. and were 
asked to compare the height of the steps with this value, as will be described below.

\section{Size Judgments}

Intrinsic. As in Experiment 1, judgments of steponability were made.

Extrinsic. At the beginning of the extrinsic session, the participants were shown the yardstick at a distance of about $50 \mathrm{~cm}$ and were told that they would be comparing the height of each block to this length. They were instructed to respond "yes" if they thought that the block was equal to or smaller than 24 in., and "no" if the block was greater than 24 in. The experimenter held the yardstick in a horizontal position, to discourage the participants from immediately scaling it to their (or the experimenter's) body. The participants were not allowed to touch the yardstick. After about $30 \mathrm{sec}$, it was hidden from view for the duration of the block of size and PEH trials.

\section{Procedure}

The procedure was identical to that of Experiment 1, except that, in the extrinsic session, the yardstick was briefly re-presented to the participants upon return from their break.

\section{Design}

The design also remained the same, except that each block of size trials contained only two sets of judgments (two ascending and two descending trials), instead of three, to shorten the duration of the experiment. ${ }^{2}$ The judgments of each set were averaged, for a total of two scores in each floor condition.

\section{Results}

\section{Size Judgments}

No participants reported noticing the false floor. Mean size judgments and critical boundaries for the size tasks, by floor condition, are shown in Figure 7. As was expected, critical boundaries in the intrinsic task were less

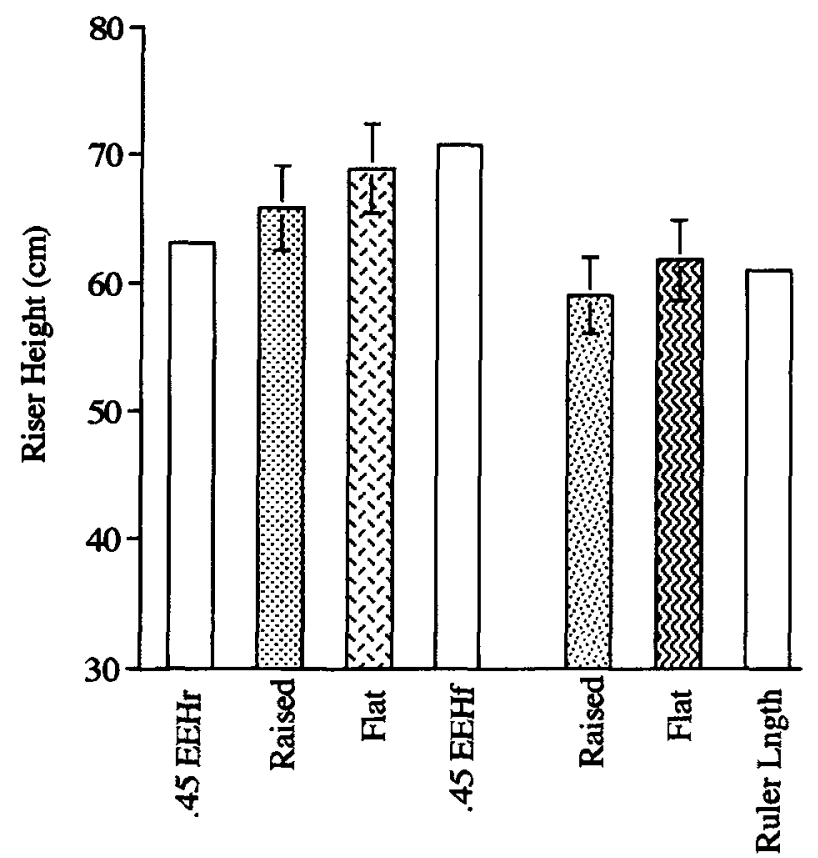

Intrinsic Extrinsic

Figure 7. Critical boundaries, judged sizes, and standard errors in Experiment 2. White bars correspond to predicted values. in the raised condition $(M=65.83 \mathrm{~cm})$ than in the flat condition $(M=68.92 \mathrm{~cm})$. Again, contrary to prediction, a similar difference appeared in the extrinsic task. Perceived step heights here were lower in the raised condition $(M=59.04 \mathrm{~cm})$ than in the flat condition $(M=$ $61.79 \mathrm{~cm}$ ). A 2 (floor order) $\times 2$ (task order) $\times 2$ (task) $\times 2$ (floor) mixed design ANOVA on mean scores revealed a main effect of task $[F(1,20)=23.03, p<.0001]$ and a main effect of floor $[F(1,20)=17.58, p<.0001]$ but no effect of floor order or task order. The predicted interaction of task $\times$ floor again failed to appear $[F(1,20)=$ $0.09, p=.772]$. However, an unpredicted three-way floor order $\times$ task order $\times$ floor interaction was significant $[F(1,20)=5.18, p<.034]$.

The right-hand column of Table 4 shows the means of difference values, obtained by subtracting raised scores from flat scores. These were essentially the same across size tasks (intrinsic, $M=3.08 \mathrm{~cm}$; extrinsic, $M=$ $2.75 \mathrm{~cm}$ ) and, again, less than half (intrinsic, $41 \%$ of $7.6 \mathrm{~cm}$; extrinsic, $42 \%$ of $6.6 \mathrm{~cm}$ ) of what the $\mathrm{EH}$ model predicts. The magnitude of this effect was not significantly different from that obtained in Experiment 1 [44\%; $t(46)=0.90, p=.371]$. As in Experiment 1, no significant correlations were found between the shifts in critical boundaries/size judgments and corresponding shifts in PEH induced by the false floor [intrinsic, $r(24)=$ $.072, p>.05$; extrinsic, $r(24)=.113, p>.05]$.

\section{Accuracy}

Constant error. For the extrinsic task, a comparison of mean judgments with the actual standard value (i.e., 24 in.) in the flat condition revealed that the participants were slightly underestimating, choosing steps that were $1 \%$ taller than the standard value; in the raised condition, the same comparison yielded a slight overestimation (3\%; Table 4). For the intrinsic task, comparison of judged critical boundaries with estimated boundaries $\left(.45 \mathrm{EEH}_{\mathrm{f}}\right.$ and .45 $\mathrm{EEH}_{\mathrm{r}}$, respectively) yielded a slight overestimation in the flat condition (3\%) and an underestimation $(5 \%)$ in the raised condition (Table 4$)$.

Variable error. In every condition, two overall size judgments were recorded for each participant. The second panel of Table 2 shows mean standard deviations of these judgments by task and floor conditions. Contrary to prediction, judgments were generally consistent, regardlèss of task. A 2 (task) $\times 2$ (floor) ANOVA performed on the standard deviations revealed no effects of task $[F(1,23)=0.09, p=.772]$ or floor $[F(1,23)=0.04, p=$ $852]$ and no significant interactions.

\section{Eye Height Judgments}

Table 5 shows mean PEH judgments by task and floor conditions, together with the corresponding predicted values of $E H_{f}$ and $E E H_{r}$. Averaged across size tasks, $\mathrm{PEH}$ in the raised condition $(M=130.91 \mathrm{~cm})$ was $11.52 \mathrm{~cm}$ less than that in the flat condition $(M=142.43 \mathrm{~cm})$. This difference was significant $[t(23)=-10.53, p<.0001]$. Judgments in both conditions were quite variable (raised, $S D=15.0 \mathrm{~cm}$; flat, $S D=15.7 \mathrm{~cm}$ ). 
Table 4

Size Judgments, Critical Boundaries, and Difference Scores (Flat - Raised) in Experiment 2

\begin{tabular}{|c|c|c|c|c|c|c|c|}
\hline \multirow[b]{3}{*}{ Task } & \multirow[b]{3}{*}{ Measure } & \multicolumn{4}{|c|}{ Condition } & & \\
\hline & & \multicolumn{2}{|c|}{ Flat } & \multicolumn{2}{|c|}{ Raised } & \multicolumn{2}{|c|}{ Difference } \\
\hline & & $M$ & $S D$ & $M$ & $S D$ & $M$ & $S D$ \\
\hline \multirow[t]{3}{*}{ Intrinsic } & Judged critical boundary & 68.92 & 10.31 & 65.83 & 9.21 & 3.08 & 3.98 \\
\hline & Estimated critical boundary & 70.74 & 4.06 & 63.09 & 4.06 & & \\
\hline & Constant error ratio & \multicolumn{2}{|c|}{1.03} & \multicolumn{2}{|c|}{0.95} & & \\
\hline \multirow[t]{3}{*}{ Extrinsic } & Judged equivalent size & 61.79 & \multirow[t]{2}{*}{10.11} & 59.04 & \multirow[t]{3}{*}{8.81} & \multirow[t]{3}{*}{2.75} & \multirow[t]{3}{*}{5.10} \\
\hline & Actual size of standard & 61.00 & & 61.00 & & & \\
\hline & Constant error ratio & \multicolumn{2}{|c|}{0.99} & 1.03 & & & \\
\hline
\end{tabular}

Note-Numbers are group means $( \pm S D)$ in centimeters. Judged critical boundaries in the intrinsic task were compared with estimates based on Mark (1987), who found that actual critical boundaries averaged .45 EH; they have been estimated at $.45 \mathrm{EEH}_{\mathrm{f}}$ and $.45 \mathrm{EEH}_{\mathrm{r}}$ for the flat and raised conditions, respectively. In the extrinsic task, the length of the standard rod was $24 \mathrm{in.}(61 \mathrm{~cm})$.

The 11.52-cm shift owing to the false floor was a modest improvement over the shift found in Experiment 1, bringing it up to $68 \%$ (as compared with $52 \%$, Experiment 1) of what would be predicted on the basis of the actual shift of its height, but still falling substantially short of it. Although larger, the effect of the false floor on PEH judgments was not significantly different from that in Experiment $1[t(46)=0.31, p=.758]$.

Averaged across size tasks, $\mathrm{PEH}$ in the flat condition was $14.77 \mathrm{~cm}$ below $\mathrm{EEH}_{\mathrm{f}}$; in the raised condition, it fell short of $E_{\mathrm{r}}$ by $9.27 \mathrm{~cm}$. A 2 (task) $\times 2$ (floor) ANOVA on difference scores (predicted values $-\mathrm{PEH}$ ) revealed a main effect of floor $[F(1,23)=24.95, p<.001]$, but no effect of task and no significant interaction. Again, underestimations were substantial, especially for judgments made when the false floor was not present. However, on the whole, these values were an improvement over the accuracy of PEH judgments obtained in Experiment $1[t(46)=$ 2.73, $p<.009]$. The participants in Experiment 2 underestimated PEH less than did the participants in Experiment 1.

\section{Discussion}

Even though the extrinsic task in this experiment required the participants to scale objects to a remembered standard, which should have reduced reliance on EH scaling, the presence of the false floor still affected judgments of perceived object height. This suggests that the use of EH information in judging object height is a general phenomenon, not confined to action tasks. This finding is in keeping with Sedgwick's (1973) horizonratio rule. Assuming that observer $\mathrm{EH}$ is a known constant, the absolute size of an object is potentially available. However, the relationship between observer EH and an object's absolute size is not specified directly; rather, an observer must explicitly convert from EH-scaled to absolute coordinates.

Although altering the position of the reduction tube aperture relative to the viewing peephole reduced the participants' tendency to underestimate PEH in Experiment 2 (as compared with that in Experiment 1), it did not eliminate underestimation completely. Nor did it increase the effect of the false floor on either PEH or size judgments. Indeed, as in Experiment 1, the shift in perceived size for both tasks was less than half of what would be predicted by the geometry of the false floor. It remains an open question as to whether frame effects, other sources of conflicting information such as ground texture elements, or a combination of both are responsible for the reduced reliance on $\mathrm{EH}$ information in these studies.

\section{EXPERIMENT 3}

The effect of the false floor on perceived object width was investigated next. The experimental procedure was essentially the same as that in Experiment 2, except that the participants judged the passability of doorwaylike apertures in the intrinsic task and the horizontal extent of the same apertures, relative to a remembered standard (18 in.) in the extrinsic task. The participants made judgments in both flat and raised conditions, and PEH judgments were obtained. According to the horizon-ratio model, horizontal dimensions in the frontoparallel plane can also be scaled relative to EEH. Warren and Whang (1987) demonstrated that manipulating EEH with a false floor produced overestimations of judged passability. The critical boundaries for this affordance corresponded to

Table 5

Perceived Eye Height (PEH) in Experiment 2

\begin{tabular}{|c|c|c|c|c|c|c|c|c|c|}
\hline \multirow[b]{2}{*}{ Condition } & \multicolumn{2}{|c|}{ Extrinsic Task } & \multicolumn{2}{|c|}{ Intrinsic Task } & \multicolumn{2}{|c|}{ Mean } & \multicolumn{2}{|c|}{ Predicted Value } & \multirow{2}{*}{$\begin{array}{c}\text { Difference } \\
(\mathrm{PEH}-\mathrm{EEH})\end{array}$} \\
\hline & $M$ & $S D$ & $M$ & $S D$ & $M$ & $S D$ & $M$ & $S D$ & \\
\hline $\begin{array}{l}\text { Flat } \\
\end{array}$ & 143.20 & 14.4 & 4 & 17. & 17 & & & & -14.77 \\
\hline Raised & 131.30 & 15.15 & 130.51 & 15.48 & 130.91 & 15.05 & 140.20 & 9.01 & -9.27 \\
\hline Difference & & & & & 11.52 & & 17.00 & & -5.50 \\
\hline
\end{tabular}

Note-Means and SDs are in centimeters. In the flat condition, the predicted value $\left(\mathrm{EEH}_{\mathrm{f}}\right)$ is the actual mean $\mathrm{EH}$ of the 24 participants. In the raised condition $\left(\mathrm{EEH}_{\mathrm{r}}\right)$, it is $17 \mathrm{~cm}$ less. 
$.29 \mathrm{EEH}$, on average. On the basis of this $\mathrm{EH}$ ratio, the false floor was expected to reduce critical passability by $4.9 \mathrm{~cm}$ in the intrinsic task $(.29 \times 17)$. Because the standard in the extrinsic task also corresponded, on average, to $29 \%$ of subjects' $\mathrm{EH}$, perceived width would also be reduced by $4.9 \mathrm{~cm}$ if EH information were used solely. However, it was again predicted that the false floor would have a greater effect on intrinsic judgments than on extrinsic ones and that intrinsic judgments would also be more accurate (in terms of constant and variable error).

\section{Method}

\section{Participants}

Twenty-four Emory undergraduates ( 17 female, 7 male) participated in the experiment as part of a class research credit requirement. Twelve more participants ( 9 female, 3 male) were added (total $=36$ ) when an analysis of the initial data indicated that the task $\times$ floor interaction approached significance. Three additional participants were excluded from the experiment because they failed to produce a response change (i.e., from "no" to "yes" or vice versa) during two consecutive trials. All the participants were tested individually; none was aware of the hypothesis being tested.

\section{Equipment}

The equipment used was essentially the same as that in Experiment 1 , except that the far end of the reduction tube was altered. The shape of this opening was changed from an oval to a $12.5 \times$ $5 \mathrm{~cm}$ rectangle ( $38^{\circ} \times 16^{\circ}$ of visual angle) and was positioned in such a manner that the peephole was $2.5 \mathrm{~cm}$ above its vertical center. This allowed the participants to see the bottom edges of the partitions, along with approximately $30 \mathrm{~cm}$ of the floor in front of them. The outer edges of the partitions and the ceiling and walls of the experimental chamber were out of the participants' view.

\section{Stimulus Materials}

An adjustable aperture was created by moving apart two $2.1 \times$ $.6 \mathrm{~m}$ white foam-core partitions. Each partition was secured to a freestanding $1.8 \times 0.5 \times 0.5 \mathrm{~m}$ wooden support tripod that remained hidden from the participants' view. The partitions were positioned parallel to the back of the experimental chamber, at a distance of $0.6 \mathrm{~m}$ from it $(4.3 \mathrm{~m}$ from the participant). The aperture width varied from 32 to $68 \mathrm{~cm}$, in 2-cm increments. The widths were marked out inconspicuously on the chamber floor (and false floor) with colored dressmaker pins, invisible from the participants' viewing position.

For the extrinsic task, the participants were shown a standard wooden yardstick (hereafter referred to as the ruler) that had been cut to 18 in. $(45.7 \mathrm{~cm})$ and were asked to compare the width of the aperture with this value.

\section{Size Judgments}

Intrinsic. The participants made a "yes" or "no" judgment as to whether they could walk through the presented aperture without turning their shoulders. The experimenter demonstrated actions illustrating both "yes" and "no" judgments. The participants were also shown the endpoints of the aperture range.

Extrinsic. As in Experiment 2, the participants were shown the ruler at the beginning of the extrinsic session. They were told to compare the width of each aperture with its remembered width. They were instructed to respond "no" if the aperture was less than 18 in., and "yes" if the aperture was equal to or greater than 18 in. The experimenter held the ruler in a vertical position, to discourage the participants from immediately scaling it to their (or the experimenter's) shoulders. As in Experiment 2, the participants were not allowed to touch the ruler, and it was hidden from view for the duration of each block of size and PEH trials.

\section{Procedure}

The procedure was essentially the same as that of Experiment 2, except that a measurement of the participants' shoulder widths was taken at the end of the experiment $(M=49.71 \pm 3.87 \mathrm{~cm})$.

\section{Design}

The design was identical to that of Experiment 2.

\section{Results}

\section{Size Judgments}

No participants reported noticing the false floor. Mean width judgments and critical size boundaries, as a function of task and floor condition, are shown in Figure 8. For the intrinsic task, perceived critical boundaries were predictably lower in the raised condition $(M=43.61 \mathrm{~cm})$ than in the flat condition $(M=45.39 \mathrm{~cm})$. The participants chose narrower aperture widths as critical boundaries in the raised condition, as compared with the flat condition. In line with the hypothesis, the mean difference between floor conditions was reduced in the extrinsic task (raised, $M=45.09 \mathrm{~cm}$; flat, $M=45.87 \mathrm{~cm}$ ). A 2 (floor order) $\times$ 2 (task order) $\times 2$ (floor) $\times 2$ (task) ANOVA revealed a main effect of floor $[F(1,32)=12.71, p<.001]$ but no effect of floor order, task order, or task. The predicted task $\times$ floor interaction approached significance $[F(1,32)=$ $3.50, p=.071]$. The false floor had more of an effect on judgments in the intrinsic than in the extrinsic task. Three other interactions were also significant. The floor order $\times$ floor interaction $[F(1,32)=5.56, p<.025]$ indicated that the false floor had a greater effect on lowering critical boundaries/width judgments when the flat condition occurred first (this is the opposite to what was found in

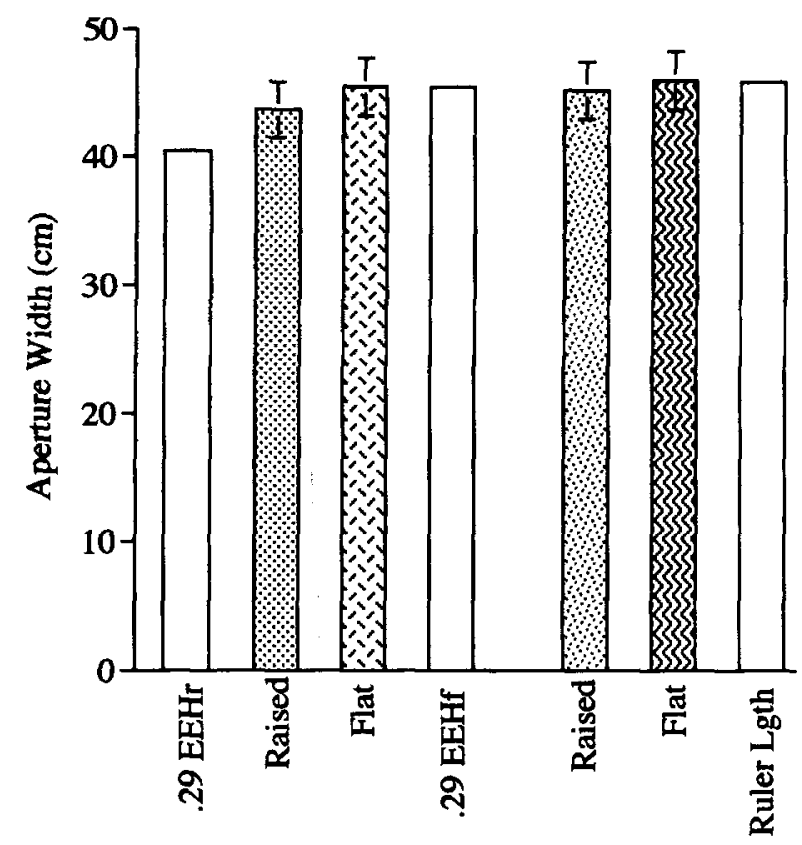

$$
\text { Intrinsic Extrinsic }
$$

Figure 8. Critical boundaries, judged sizes, and standard errors in Experiment 3. White bars correspond to predicted values. 
Experiment 1). The task order $\times$ floor interaction $[F(1,32)=4.02, p<.05]$ indicated that flat judgments were highest when the intrinsic task preceded the extrinsic task. The floor order $\times$ task order $\times$ task $\times$ floor interaction was also significant $[F(1,32)=3.98, p<.05]$.

The right-hand column of Table 6 shows the means of the difference scores, obtained by subtracting raised size scores from flat ones. Unlike Experiments 1 and 2, the effect of the false floor was markedly less in the extrinsic $(M=0.78 \mathrm{~cm})$ than in the intrinsic $(M=1.78 \mathrm{~cm})$ task. The latter value was about one third $(36 \%)$ of what was predicted by the EH model $(4.9 \mathrm{~cm})$; the former, one sixth $(16 \%)$.

\section{Accuracy}

Constant error. For the extrinsic task, a comparison of mean judgments with the actual standard value (i.e., 18 in.) revealed near-perfect accuracy in both floor conditions (flat, $0 \%$ overestimation; raised, $1 \%$ overestimation; Table 6).

For the intrinsic task, two ratios were calculated, following Warren and Whang (1987). The first takes into account shoulder width only and is defined by AW/SW, where $\mathrm{AW}=$ judged aperture width and $\mathrm{SW}=$ actual shoulder width. The data from Warren and Whang's sample yielded an SW ratio of 1.16: the participants tended to underestimate aperture widths, leaving a comfortable margin of error for passability. The present SW ratio, computed by dividing critical aperture boundaries (from the intrinsic flat condition) by SW, was 0.91 : The participants chose apertures that were less than actual shoulder width (i.e., they tended to overestimate the aperture widths). However, when critical aperture boundaries were transformed into proportions of EEH, the resulting EH ratios $\left(.29 \mathrm{EEH}_{\mathrm{f}}\right.$ in the flat condition; $.31 \mathrm{EEH}_{\mathrm{r}}$ in the raised condition) were very close to the corresponding $\mathrm{EH}$ ratio of Warren and Whang (.29). Comparisons of judged critical boundaries with values estimated from .29 EEH revealed perfect accuracy in the flat condition $(0 \%)$ and underestimations in the raised condition (7\%; Table 6).

Variable error. In every condition, two overall judgments were recorded for each participant. The third panel of Table 2 shows mean standard deviations for these judgments by task and floor conditions. Contrary to prediction, judgments were generally consistent, regardless of task. A 2 (task) $\times 2$ (floor) ANOVA performed on the standard deviations revealed no effects of task $[F(1,35)=$ $2.31, p=.137]$ or floor $[F(1,35)=0.5, p=.827]$ and no significant interactions.

\section{Eye Height Judgments}

Table 7 shows the means for all four PEH conditions, together with corresponding $\mathrm{EEH}_{\mathrm{f}}$ and $\mathrm{EEH}_{\mathrm{r}}$ values. $\mathrm{Av}$ eraged across size tasks, mean $\mathrm{PEH}$ in the raised condition $(M=126.12 \mathrm{~cm})$ was $12.46 \mathrm{~cm}$ less than in the flat condition $(M=138.58 \mathrm{~cm})$. This difference was significant $[t(35)=14.35, p<.0001]$. Judgments in both conditions were also quite variable (raised, $S D=13.96 \mathrm{~cm}$; flat, $S D=13.85 \mathrm{~cm}$ ).

The mean PEH difference, between floor conditions, of $12.46 \mathrm{~cm}$ was about three fourths $(74 \%)$ of what would be predicted by the actual height of the false floor $(17 \mathrm{~cm})$.

Judged EHs were lower than actual EHs. Averaged across size tasks, $\mathrm{PEH}$ in the flat condition was $17.85 \mathrm{~cm}$ below $\mathrm{EEH}_{\mathrm{f}}$; in the raised condition, mean $\mathrm{PEH}$ was $13.31 \mathrm{~cm}$ below $\mathrm{EEH}_{\mathrm{r}}$. This difference was significant $[t(35)=-5.23, p<.0001]$, indicating again that the participants' PEH judgments were more accurate (i.e., they were underestimated less) when the false floor was present.

\section{Discussion}

The results of Experiment 3 were as predicted: A dissociation was found between the use of $\mathrm{EH}$ information for affordance and that for apparent-size width tasks. The presence of the false floor reduced the participants' judgments of aperture passability but did not affect comparisons of the same stimuli with a remembered standard. These results differ from those of Experiments 1 and 2, on perceived height, where the effects of the false floor on perceived critical boundaries (intrinsic task) and riser height judgments (extrinsic task) were similar. How can this contradiction be reconciled? One explanation is that EH may be a more natural metric for judgments of object height than for those of width. An object's vertical dimension and observer EH coexist in the same axis of space. In contrast, the dimension of width is specified only

Table 6

Size Judgments, Critical Boundaries, and Difference Scores (Flat - Raised) in Experiment 3

\begin{tabular}{|c|c|c|c|c|c|c|c|}
\hline \multirow[b]{3}{*}{ Task } & \multirow[b]{3}{*}{ Measure } & \multicolumn{4}{|c|}{ Condition } & & \\
\hline & & \multicolumn{2}{|c|}{ Flat } & \multicolumn{2}{|c|}{ Raised } & \multicolumn{2}{|c|}{ Difference } \\
\hline & & $M$ & $S D$ & $M$ & $S D$ & $M$ & $S D$ \\
\hline \multirow[t]{3}{*}{ Intrinsic } & Judged critical boundary & 45.39 & 4.15 & 43.61 & 4.47 & 1.78 & 3.01 \\
\hline & Estimated critical boundary & 45.36 & 2.57 & 40.43 & 2.57 & & \\
\hline & Constant error ratio & \multicolumn{2}{|c|}{1.00} & \multicolumn{2}{|c|}{0.93} & & \\
\hline \multirow[t]{3}{*}{ Extrinsic } & Judged equivalent size & 45.87 & 5.55 & 45.09 & 4.97 & 0.78 & 2.85 \\
\hline & Actual size of standard & 45.72 & & 45.72 & & & \\
\hline & Constant error ratio & \multicolumn{2}{|c|}{1.00} & \multicolumn{2}{|c|}{1.01} & & \\
\hline
\end{tabular}

Note-Numbers are group means $( \pm S D)$ in centimeters. Judged critical boundaries in the intrinsic condition were compared with estimates based on Warren and Whang (1987). They found that actual critical boundaries averaged $.29 \mathrm{EH}$; these have been estimated at $.29 \mathrm{EEH}_{\mathrm{f}}$ and $.29 \mathrm{EEH}_{\mathrm{r}}$ for the flat and raised conditions, respectively. In the extrinsic task, the length of the standard rod was $18 \mathrm{in} .(45.72 \mathrm{~cm})$. 
Table 7

Perceived Eye Height (PEH) in Experiment 3

\begin{tabular}{|c|c|c|c|c|c|c|c|c|c|}
\hline \multirow[b]{2}{*}{ Condition } & \multicolumn{2}{|c|}{ Extrinsic Task } & \multicolumn{2}{|c|}{ Intrinsic Task } & \multicolumn{2}{|c|}{ Mean } & \multicolumn{2}{|c|}{ Predicted Value } & \multirow{2}{*}{$\begin{array}{c}\text { Difference } \\
\text { (PEH - EEH) }\end{array}$} \\
\hline & $M$ & $S D$ & $M$ & $S D$ & $M$ & $S D$ & $M$ & $S D$ & \\
\hline flat & 138. & & & & 1385 & & & 8.5 & -17.85 \\
\hline Raised & & 14.68 & & & 126.12 & 13.96 & 139.43 & 8.57 & -13.31 \\
\hline Difference & & & & & 12.46 & & 17.00 & & -4.54 \\
\hline
\end{tabular}

Note-Means and $S D \mathrm{~s}$ in centimeters. In the flat condition, the predicted value $\left(\mathrm{EEH}_{\mathrm{f}}\right)$ is the actual mean $\mathrm{EH}$ of the 24 participants. In the raised condition $\left(\mathrm{EEH}_{\mathrm{r}}\right)$, it is $17 \mathrm{~cm}$ less.

tangentially to observer EH. Thus, the object height/EH relationship is immediately accessible, whereas the width/EH relationship is not. In width tasks not requiring overt body scaling, the human visual system may overlook $\mathrm{EH}$ information, in lieu of other available sources.

Another possibility is that width judgments of an aperture per se (i.e., the horizontal space between two objects, rather than the actual width of an object) are less susceptible to manipulations of EEH because apertures are not continuous surfaces. However, the results of the intrinsic task, where an effect of the false floor was found on judgments of aperture passability, render this explanation unlikely.

A final possibility is that the results may be due merely to methodological inconsistencies between height and width experiments. For example, the introduction of a rectangular aperture opening in Experiment 3 may have inadvertently caused other sources of information, such as units of floor texture or the aperture frame itself, to become more salient. This issue was addressed in Experiment 4.

Although the presence of the false floor significantly reduced perceived critical boundaries in the intrinsic condition, the mean effect (36\%) was markedly less than the effect reported by Warren and Whang (1987) (65\%) for a similar task. Several factors may account for this difference. Warren and Whang used a between-subjects design in their experiment: Different participants performed in flat and raised conditions. The present design, although within- subjects, may be less sensitive to capturing the use of EH scaling. On the other hand, in the present setup, objects on the false floor were raised $17 \mathrm{~cm}$ off the normal floor and appeared at a distance of $4.3 \mathrm{~m}$ from the participant, for a total decrease in fieldof-view visual angle (from visible floor to observer's line of gaze) of $2^{\circ}$. In Warren and Whang's experiment, the false floor raised objects a greater distance $(21.5 \mathrm{~cm})$ off the floor, and they appeared at a closer distance of $2.2 \mathrm{~m}$, for a total decrease in visual angle of $4^{\circ}$. It is, thus, possible that the magnitude of the decrease in field-of-view visual angle created by the the false floor plays a role in eliciting shifts in perceived size.

\section{EXPERIMENT 4}

The final experiment was an attempt to replicate Experiment 3's main finding that extrinsic width tasks do not require the use of EH scaling. However, instead of contrasting the effects of the false floor on different types of tasks, its effects on judgments of different object dimensions - height and width-were compared within an extrinsic paradigm. That is, the participants again participated in two sessions, but both required them to compare stimuli with a remembered value of 18 in. In one session, the participants judged the height of the steps (as in Experiments 1 and 2); in the other, they judged the width of apertures (as in Experiment 3). In this way, it was possible to assess in a more controlled manner the degree to which EH scaling is used outside of overt bodyscaling tasks such as perceived steponability and passability. Because the 18-in. standard corresponded to $29 \%$ of the participants' EH on average, reliance on the false floor was expected to produce $4.9-\mathrm{cm}$ reductions in perceived size in both tasks. However, it was predicted that an effect of the false floor similar to that of Experiments 1 and 2 would be found for the height task but that this effect would be absent or reduced in the width task.

\section{Method}

\section{Participants}

Twenty-four Emory undergraduates ( 16 female, 8 male) participated in the experiment as part of a class research credit requirement. Four additional participants were excluded from the study: 1 for not following directions, and 3 for failing to produce a response change (i.e., from "yes" to "no," or vice versa) on two consecutive trials. All the participants were tested individually; none was aware of the hypothesis being tested.

\section{Equipment}

The same equipment as that in Experiment 3 was used, including the rectangular-aperture viewing tube.

\section{Stimulus Materials}

For the height task, a subset of the foam-core steps from Experiment 1 was used, and two additional steps were built, to approximate as closely as possible the range of stimuli used in Experiment 3. Ten steps, ranging in height from 30.5 to $66.5 \mathrm{~cm}\left(4^{\circ}-9^{\circ}\right.$ visual angle) in 4-cm increments, were positioned $4.3 \mathrm{~m}$ from the participant.

For the width task, the foam-core partitions from Experiment 3 were used. The aperture width ranged from 30.5 to $66.5 \mathrm{~cm}$ in $4-\mathrm{cm}$ increments (same as in the height task).

In both tasks, the 18-in. wooden ruler from Experiment 3 was used as the standard comparison.

\section{Size Judgments}

At the beginning of both sessions, the participants were shown the ruler and were told to compare the height of each step (height task) or the width of each aperture (width task) with its remembered value. They were instructed to respond "yes" if the stimulus was equal to or greater than 18 in., and "no" if the stimulus was less than 
18 in. The experimenter held the ruler in a horizontal position while explaining the height task and in a vertical position while explaining the width task. As in the previous experiments, the endpoints of each range of stimuli were shown to the participants before actual testing.

\section{Procedure}

The procedure was identical to that in Experiment 3, except that both sessions required an extrinsic task and differed only on what object dimension (i.e., height or width) was tested. No body measurements were taken.

\section{Design}

The orders of the two size tasks (height and width) and the two floor conditions (flat and raised) were counterbalanced across participants. Otherwise, the design was identical to that in Experiment 3.

\section{Results}

\section{Size Judgments}

No participants reported noticing the false floor. Mean size judgments, as a function of task and floor conditions, are shown in Figure 9. For the height task, perceived riser heights were lower in the $\operatorname{raised}(M=38.54 \mathrm{~cm})$, as compared with the flat $(M=41.25 \mathrm{~cm})$, condition, as was predicted. This result is similar to those obtained for the extrinsic task of Experiments 1 and 2. In contrast, and also in line with the predictions, the mean difference between floor conditions in the width task was negligible (raised, $M=43.13 \mathrm{~cm}$; flat, $M=43.83 \mathrm{~cm}$ ). A 2 (floor order) $\times 2$ (task order) $\times 2$ (floor) $\times 2$ (task) ANOVA revealed a main effect of floor $[F(1,20)=10.16, p<.005]$ and a main effect of task $[F(1,20)=14.28, p<.001$; see the Accuracy section, below, for a discussion]. Most im-

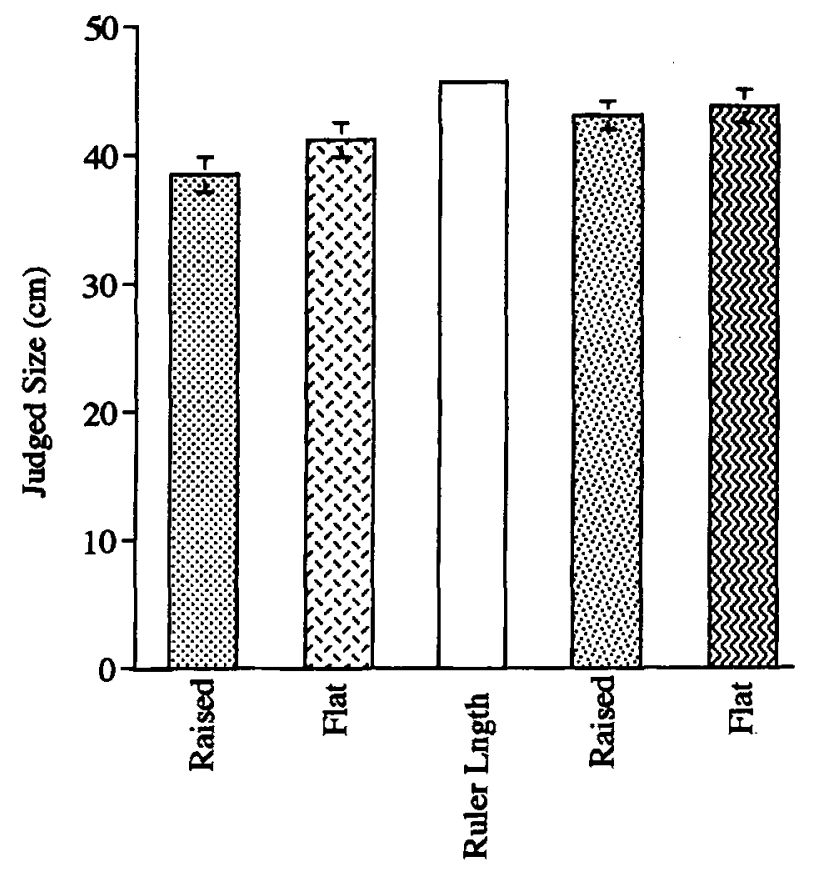

Height

Width

Figure 9. Judged sizes and standard errors in Experiment 4. The white bar corresponds to actual ruler length. portant to the hypothesis, the task $\times$ floor interaction was significant $[F(1,20)=7.63, p<.012]$. No other significant interactions were found.

The right-hand column of Table 8 shows the means of difference scores obtained by subtracting raised scores from flat ones. As in Experiment 3, the effect of the false floor was diminished in the width task $(M=0.70 \mathrm{~cm})$, approximating only $14 \%$ of the value predicted by the EH model $(4.9 \mathrm{~cm})$. In the height task, the effect of the false floor was greater $(55 \% ; M=2.71 \mathrm{~cm})$, and even larger than the magnitude of the effects found in the extrinsic tasks of Experiments 1 and 2 (Experiment 1, 42\%; Experiment 2, 42\%). Furthermore, a significant correlation was found between shifts in size judgments and corresponding shifts in $\mathrm{PEH}$ induced by the false floor for the height task $[r(24)=.535, p<.01]$, but not for the width task $[r(24)=.200, p>.05]$. These findings provide additional support for the notion that $\mathrm{EH}$ information was used to scale the object heights but not the widths.

\section{Accuracy}

Constant error. A comparison of participants' mean judgments in each task with the actual standard value (i.e., 18 in.) revealed that width judgments were more accurate than height judgments. Slight overestimations were found in width (flat, $4 \%$; raised, $6 \%$; Table 8 ), and significantly greater overestimations (as evidenced in the main effect of task; see the Size Judgments section, above) were found in height (flat, 11\%; raised, 19\%; Table 8 ).

Variable error. Two overall judgments were recorded for each participant in every condition. The fourth panel of Table 2 shows the mean standard deviations of these judgments by task and floor conditions. Judgments were more consistent in the height task. A 2 (task) $\times 2$ (floor) ANOVA performed on the standard deviations revealed a main effect of task $[F(1,23)=6.83, p<.016]$ but no effect of floor $[F(1,23)=0.52, p=.477]$ and no interactions.

\section{Eye Height Judgments}

Table 9 shows mean PEH judgments for all four conditions, together with corresponding $\mathrm{EEH}_{\mathrm{f}}$ and $\mathrm{EEH}_{\mathrm{r}}$ values. Averaged across tasks, mean PEH in the raised condition $(M=122.55 \mathrm{~cm})$ was $12.62 \mathrm{~cm}$ less than in the flat condition $(M=135.17 \mathrm{~cm})$. This difference was significant $[t(23)=13.47, p<.0001]$. Judgments in both conditions were also highly variable (raised, $S D=$ $21.50 \mathrm{~cm}$; flat, $S D=23.82 \mathrm{~cm}$ ).

The mean PEH difference, between floor conditions, of $12.62 \mathrm{~cm}$ was about three fourths $(74 \%)$ of what was predicted by the actual height of the false floor $(17 \mathrm{~cm})$. The magnitude of this effect was similar to that obtained with the same viewing aperture in Experiment 3 (73\%).

Judged EHs were appreciably below actual EHs. Averaged across tasks, PEH in the flat condition was $22.47 \mathrm{~cm}$ below $\mathrm{EEH}_{\mathrm{f}}$; in the raised condition, it fell below $E E H_{\mathrm{r}}$ by $18.09 \mathrm{~cm}$. This difference was significant $[t(23)=-4.76, p<.0001]$. PEH judgments were again underestimated less when the false floor was present. 
Table 8

Size Judgments and Difference Scores (Flat - Raised) in Experiment 4

\begin{tabular}{|c|c|c|c|c|c|c|c|}
\hline \multirow[b]{3}{*}{ Task } & \multirow[b]{3}{*}{ Measure } & \multicolumn{4}{|c|}{ Condition } & & \\
\hline & & \multicolumn{2}{|c|}{ Flat } & \multicolumn{2}{|c|}{ Raised } & \multicolumn{2}{|c|}{ Difference } \\
\hline & & $M$ & $S D$ & $M$ & $S D$ & $M$ & $S D$ \\
\hline \multirow[t]{3}{*}{ Height } & Judged equivalent size & 41.25 & \multirow[t]{2}{*}{6.67} & 38.54 & \multirow[t]{2}{*}{6.71} & \multirow[t]{2}{*}{2.71} & \multirow[t]{2}{*}{2.58} \\
\hline & Actual size of standard & 45.72 & & 45.72 & & & \\
\hline & Constant error ratio & & & & & & \\
\hline \multirow[t]{3}{*}{ Width } & Judged equivalent size & 43.83 & \multirow[t]{2}{*}{6.10} & 43.13 & \multirow[t]{3}{*}{5.45} & \multirow[t]{3}{*}{0.71} & \multirow[t]{3}{*}{3.34} \\
\hline & Actual size of standard & 45.72 & & 45.72 & & & \\
\hline & Constant error ratio & \multicolumn{2}{|c|}{1.04} & 1.06 & & & \\
\hline
\end{tabular}

Note-Numbers are group means $( \pm S D)$ in centimeters. In both tasks, the length of the standard rod was 18 in. $(45.72 \mathrm{~cm})$.

The magnitude of these underestimations was similar to those found in Experiment 1 (flat, $25.76 \mathrm{~cm}$; raised, $17.54 \mathrm{~cm}$ ), despite the fact that the viewing peephole was better centered on the vertical extent of the reduction tube in the present experiment. A closer inspection of the data revealed that the greater underestimation was due to the aberrant judgments of 3 participants, whose mean underestimation was huge: $52.87 \mathrm{~cm}$ in the flat condition (range, $42.10-70.60 \mathrm{~cm}$ ) and $63.92 \mathrm{~cm}$ in the raised condition (range, $52.70-85.70 \mathrm{~cm}$ ).

\section{Discussion}

The main results of Experiment 4 were as expected. For the third time, an effect of the false floor was found on judged height within an extrinsic task. This finding was bolstered by the appearance of a significant correlation between effects of the false floor on size judgments and those on PEH judgments for height only. These results provide the strongest evidence to date that $\mathrm{EH}$ information is used to scale the vertical extents of objects. On the other hand, in support of the results of Experiment 3 , no effect of the false floor was found on an identical task involving judged width.

Further support for this dissociation was found in the analysis of accuracy. In terms of constant error, width judgments were less biased than height judgments. However, significantly greater overestimations in the latter presumably resulted from reliance on underestimated PEH. On the other hand, the EH-scaled height judgments were more internally consistent than the width judgments, as assessed by variable error. Taken together, these findings indicate that the use of EH information for judging object size may be a general strategy for the dimension of object height, but not of width.
This finding may be curious, but it is not new. A similar dissociation involving the perception of height and width has been reported by Gillam $(1980,1995)$. She found that horizontal and vertical pairs of lines presented against equivalent texture backgrounds were treated differently by viewers. An effect of background scaling only occurred when the test lines and background texture elements shared the same dimension (e.g., vertical line against compression gradient, horizontal line against perspective gradient). When line/texture dimensions were misaligned, there was no effect of scaling. This explanation also applies to the present results. EH scaling of apparent height occurs because an object's vertical dimension and observer EH are both specified in the vertical axis of space. Apparent width is unaffected by EH, because the dimension of width is specified in the horizontal axis, orthogonal to observer EH.

The effect of the false floor on height judgments was similar to that in Experiments 1 and 2 but still fell substantially short of what was predicted by the horizon-ratio model. It is reasonable to assume that whatever source of information participants used in the width task (which presumably conflicted with EEH information) was also used, at least partially, in the height task, producing the middling false floor effect. In the present setup, ratios of floor texture units remained a viable alternative and would have been especially effective in gauging aperture widths.

\section{GENERAL DISCUSSION}

The results of these experiments help to clarify the conditions under which EH information is used to scale object sizes. In line with the EH model developed by proponents of the ecological view of perception (Gibson,

Table 9

Perceived Eyé Height (PEH) in Experiment 4

\begin{tabular}{|c|c|c|c|c|c|c|c|c|c|}
\hline \multirow[b]{2}{*}{ Conditions } & \multicolumn{2}{|c|}{ Extrinsic Task } & \multicolumn{2}{|c|}{ Intrinsic Task } & \multicolumn{2}{|c|}{ Mean } & \multicolumn{2}{|c|}{ Predicted Value } & \multirow{2}{*}{$\begin{array}{c}\text { Difference } \\
(\mathrm{PEH}-\mathrm{EEH})\end{array}$} \\
\hline & $M$ & $S D$ & $M$ & $S D$ & $M$ & $S D$ & $\bar{M}$ & $S D$ & \\
\hline Flat & 134.57 & 24.97 & 135.78 & 23.52 & 135.17 & 23.82 & 157.64 & 8.51 & -22.47 \\
\hline Raised & 121.56 & 22.87 & 123.55 & 20.69 & 122.55 & 21.50 & 140.64 & 8.51 & -18.09 \\
\hline Difference & & & & & 12.62 & & 17.00 & & -4.38 \\
\hline
\end{tabular}

Note-Means and $S D$ s are in centimeters. In the flat condition, the predicted value $\left(\mathrm{EEH}_{\mathrm{f}}\right)$ is the actual mean $\mathrm{EH}$ of the 24 participants. In the raised condition $\left(\mathrm{EEH}_{\mathrm{r}}\right)$, it is $17 \mathrm{~cm}$ less. 
1979; Mark, 1987; Sedgwick, 1973; Warren \& Whang, 1987), manipulation of EEH produces corresponding biases in affordance judgments. However, the results suggest that EH scaling is not limited to affordances; it is also used in perceiving the apparent height of objects. The participants judging the vertical extent of objects (Experiments 1,2 , and 4 ) related this dimension to their own EHs, regardless of whether they were making an action or an apparent-size judgment. However, object width (Experiments 3 and 4) was scaled to EH only when an affordance task was involved. Thus, the use of $\mathrm{EH}$ as a metric for size appears to be constrained by environmental properties, as well as by behavioral potentialities.

This difference may be due to the way EH information is specified, relative to the object dimensions of height and width, in the optic array. Gillam (1995, p. 51) has suggested that the visual system has more difficulty processing some geometries than others. The present results seem to support this notion. An object's vertical dimension and observer EH are both present in the vertical axis of space. Moreover, the object height/EH ratio is invariant over multiple viewpoints of the observer. Regardless of whether an object is viewed head-on or from an angle, its height still takes up the same proportion of observer EH. In contrast, EH and object width are specified tangentially with respect to each other, and this ratio changes with observer viewpoint. As a result, the visual system may have evolved to be more attuned to the object height /EH relationship.

The results of our experiments suggest that participants are attuned to these differences in $\mathrm{EH}$ accessibility. The notion that environmental information is attended to selectively, depending on its utility, has been suggested before. Research on dynamic event perception (Gilden \& Proffitt, 1989, 1994; Proffitt \& Gilden, 1989; Todd, 1981) has shown that people solve complex motion problems by isolating the one salient source of information of an event and applying to it a heuristic, or rule, based on previous experience. For instance, in judging the relative mass of two colliding balls, a participant will focus on the relative velocity of the balls after collision and utilize the heuristic "light balls travel faster" to solve the problem. Such a strategy enables people to perceive key aspects of events without having to integrate all the sources of information.

It appears that a related strategy may be used in size perception. People attend to the information in the optic array that is most useful with respect to the key dimension of the object. More importantly, size perception does not depend in fixed ways on such sources of information as eye height, floor texture, or perceived distance and retinal image size. The results of these experiments suggest a basic flexibility within the visual system to attune selectively to various sources of information.

In general, no differences in accuracy were found between intrinsic and extrinsic tasks. Despite the fact that the extrinsic tasks required reference to an arbitrary standard, the participants performed them with the same precision and accuracy as they did the more ecologically valid affordance tasks. This suggests that the distinction between intrinsic and extrinsic measures is not as strong as has previously been thought. Moreover, the visual system appears to have no problem translating from EH-scaled to absolute coordinates. In the comparison between two extrinsic tasks (Experiment 4), EH scaling of object height actually resulted in greater consistency of judgments. Perhaps this is because many absolute coordinates, such as the inch and the foot, were originally derived from dimensions of the body. Rather than treating intrinsic and extrinsic measures as being disparate, it might be more beneficial to consider them as being on a continuum.

It might be argued that changes in perceived size induced by the false floor were not due to reliance on EH at all but on distance cues, such as height in the field. This alternative was not tested directly, but it seems unlikely for two reasons. First, the method of shifting EEH was identical to that used by Warren and Whang (1987). They empirically demonstrated that the introduction of a false floor into participants' field of view produced shifts in perceived height but not in perceived distance. Second, assuming that reliance on distance cues reflects a basic underlying size mechanism, there is no logical explanation for the dissociation in false floor effects found in Experiments 3 and 4. The cue of height in the field was equally available across intrinsic, extrinsic, height, and width conditions. If it played a dominant role in the participants' judgments, all the conditions would have been equally affected.

In all of the experiments, however, the presence of the false floor reduced perceived size/critical boundaries by an amount that was, at most, half of what the EH model predicted. This indicates that the participants did rely on other sources of information, not just when judging object width, but when judging height as well. A plausible candidate was ratios of floor texture elements: The steps and apertures took up the same number of texture elements, regardless of floor condition. If attended to, the texture information would have conflicted with EH information, thus reducing its effect. This hypothesis is supported by the results of recent studies on the effects of posture on perceived size (Wraga, 1999). Under monocular experimental conditions comparable with the present research, participants judged the height of rectangular targets in several postures, including seated, standing, and lying prone. We found that the participants used $\mathrm{EH}$ information for seated and standing judgments but used a different source-ratios of texture-in the prone condition. (Floor texture is especially salient when one is lying prone.) These findings provide further evidence that the visual system exhibits flexibility in determining what information in the optic array is most useful.

The lability of the perceived EH judgments also merits discussion. In Experiment 1, monocular PEH judgments made through a reduction tube resulted in underestimations that varied by floor condition. It is likely that these underestimations were due to the positioning of the viewing peephole, which was slightly above the vertical 
center of the reduction tube, and thus may have caused an inadvertent downward slant of participants' line of gaze. Overall PEH accuracy was improved in Experiment 2 simply by lowering the position of the viewing peephole with respect to the vertical extent of tube. The finding that $\mathrm{PEH}$ judgments are susceptible to environmental biases is not new (Matin \& Fox, 1989; Matin \& Li, 1992; Stoper \& Cohen, 1989), although the magnitude of underestimation in the present studies is greater than what others reported. A recent study by Post, Welch, and Clark (1996) may shed light on the issue. Post et al. have suggested that PEH may be subsumed by a more basic mechanism related to the natural resting position of the eye relative to the head. They found that the line of gaze resulting from this so-called resting eye reflex tends to be lower than that of PEH. It is, thus, possible that the framing effect of the viewing tube in the present studies was driven by the resting eye reflex.

Whatever the explanation, the underestimations of PEH do not detract from the main finding that manipulating EEH produces corresponding shifts in perceived size. Moreover, the PEH task is contrived to the extent that EH scaling does not require explicit recognition of one's line of gaze in the environment (Mark, 1987; Warren \& Whang, 1987). According to the ecological perspective, the geometric relationship between EEH and an object's dimensions is directly specified within the optic array and does not require cognitive mediation or awareness. It is this specification of EEH information that is relevant to size perception. $\mathrm{PEH}$, on the other hand, is an artifact of the laboratory, intended merely as an index of such EH-scaled information. Further studies on EH should take these considerations into account in order to develop more authentic measures of PEH.

In sum, the present results indicate that $\mathrm{EH}$ is used as a source of information for object height, even in tasks that do not require overt reference to the observer's body. Object widths, in contrast, are only scaled to observer EH in the context of action-oriented tasks, such as the passability of doorways. More abstract width tasks rely on other sources of information, perhaps including ground texture elements. These tendencies suggest a basic flexibility within the visual system: Size perception is based on whatever information in the environment is most readily accessible.

\section{REFERENCES}

Bingham, G. P. (1993). Perceiving the size of trees: Biological form and the horizon ratio. Perception \& Psychophysics, 54, 485-495.

FiTch, H., \& TURVEY, M. T. (1978). On the control of activity: Some remarks from an ecological point of view. In D. Landers \& R. Christina (Eds.), Psychology of motor behavior and sport (pp. 3-35). Urbana, IL: Human Kinetics Publishers.

GiBson, J. J. (1950). The perception of the visual world. Boston: Houghton Mifflin.

Grison, J. J. (1977). The theory of affordances. In R. Shaw \& J. Bransford (Eds.), Perceiving, acting, and knowing: Toward an ecological psychology (pp. 67-82). Hillsdale, NJ: Erlbaum.
GIBSON, J. J. (1979). The ecological approach to visual perception. Boston: Houghton Mifflin.

GiLden, D. L., \& ProffitT, D. R. (1989). Understanding collision dynamics. Journal of Experimental Psychology: Human Perception \& Performance, 15, 372-383.

Gilden, D. L., \& Proffit, D. R. (1994). Heuristic judgment of mass ratio in two-body collisions. Perception \& Psychophysics, 56, 708-720.

Gillam, B. (1980). Geometric illusions. Scientific American, 242 (1), 102-111.

GILLAM, B. (1995). The perception of spatial layout from static optical information. In W. Epstein \& S. Rogers (Eds.), Perception of space and motion (pp. 23-67). San Diego: Academic Press.

HeLmholtz, H. von (1962). Treatise on physiological optics (Vol. 3; J. P. C. Southall, Trans.). New York: Dover. (Original work published 1867)

HoLwAY, A. H., \& Boring, E. G. (1941). Determinants of apparent visual size with distance variant. American Journal of Psychology, 54, 21-37.

KoFFKA, K. (1935). Principles of Gestalt psychology. New York: Harcourt Brace.

Leibowitz, H. W., Pollard, S. W., \& Dickerson, D. (1966). Monocular and binocular size-matching as a function of distance at various age levels. American Journal of Psychology, 79, 263-268.

MARK, L. S. (1987). Eyeheight-scaled information about affordances: A study of sitting and stair climbing. Journal of Experimental Psychology: Human Perception \& Performance, 13, 361-370.

MARK, L. S., \& VogELE, D. (1987). A biodynamic basis for perceived categories of action: A study of sitting and stair climbing. Journal of Motor Behavior, 19, 367-384.

Matin, L., \& Fox, C. R. (1989). Visually perceived eye level and perceived elevation of objects: Linearly additive influences from visual field pitch and from gravity. Vision Research, 29, 315-324.

Matin, L., \& LI, W. (1992). Visually perceived eye level: Changes induced by a pitched-from-vertical 2-line visual field. Journal of Experimental Psychology: Human Perception \& Performance, 18, 257-289.

Post, R. B., WeLCh, R. B., \& ClaRK, V. D. (1996, November). Visually perceived eye level: Effects of pitch perception and eye position. Paper presented at the 37th Annual Meeting of the Psychonomic Society, Chicago.

ProffitT, D. R., \& Gilden, D. L. (1989). Understanding natural dynamics. Journal of Experimental Psychology: Human Perception \& Performance, 15, 384-393.

ROGERS, S. (1996). The horizon-ratio relation as information for relative size in pictures. Perception \& Psychophysics, 58, 142-152.

SEDGwick, H. A. (1973). The visible horizon: A potential source of visual information for the perception of size and distance. Dissertation Abstracts International, 34, 1301B-1302B. (University Microfilms No. 73-22530)

STOPER, A. E. (1990, November). Pitched environments and apparent height. Paper presented at the 31 st Annual Meeting of the Psychonomic Society, New Orleans.

STOPER, A. E., \& BAUTISTA, A. (1992, May). Apparent height as a function of pitched environment and task. Paper presented at ARVO, Sarasota, FL.

STOPER, A. E., \& CoHEN, M. M. (1989). Effect of structured visual environments on apparent eye level. Perception \& Psychophysics, 46, 469-475.

Todo, J. T. (1981). Visual information about moving objects. Journal of Experimental Psychology: Human Perception \& Performance, 7, 795-810.

WARREN, W. H. (1984). Perceiving affordances: Visual guidance of stair climbing. Journal of Experimental Psychology: Human Perception \& Performance, 10, 683-703.

WARREN, W. H., \& WHANG, S. (1987). Visual guidance of walking through apertures: Body-scaled information for affordances. Joumal of Experimental Psychology: Human Perception \& Performance, 13, 371-383.

WraGA, M. (1999). Using eye height in different postures to scale the heights of objects. Journal of Experimental Psychology: Human Perception \& Performance, 25, 518-530.

WRAGA, M., \& NEISSER, U. (1995). Effective eye height as a determinant 
of perceived size and distance: Four exploratory studies (Rep. No. 32). Atlanta: Emory University Cognition Project.

\section{NOTES}

1. Ideally, the numerical equivalent of mean critical riser height should have been used; however, because that value was an uncommon metric (28 in.) and, hence, might have affected judgment accuracy, the more common 24 in. was used. This discrepancy between intrinsic and extrinsic standards was expected to show up as a main effect of task, with extrinsic judgments being smaller than intrinsic ones.
2. This decision was justified by the following analysis: A 2 (task) $\times$ 3 (block) ANOVA performed on the raw size judgments of Experiment 1 revealed that the participants' performance in the third block of trials did not differ significantly from that of the first two blocks, for either size task.

(Manuscript received December 18, 1996; revision accepted for publication March 9, 1998.)

\section{Nominations for the Editorship of Psychobiology}

Nominations are solicited for the editorship of Psychobiology. The term of the present editor, Raymond Kesner, expires at the end of 2000. The new editor will begin an official 4- or 5-year term on January 1, 2001, and will begin to receive manuscripts early in April 2000. The Publications Committee of the Psychonomic Society expects to appoint the new editor by December 1999.

Nominations (including self-nominations) should be submitted by July 1, 1999, to:

Michael I. Posner

Chair, Psychobiology Search Committee

Department of Psychiatry, Box 171

Cornell Medical College

525 E. 68th St.

New York, NY 10021 